\title{
Effects of IGSS' job aids-assisted Balanced Counseling Algorithms on quality of care and client outcomes
}

\author{
Federico R. Leon \\ Carlos Brambila \\ Marisela de la Cruz \\ John H. Bratt \\ Gustavo Gutierrez
}

See next page for additional authors

Follow this and additional works at: https://knowledgecommons.popcouncil.org/departments_sbsr-rh

Part of the Demography, Population, and Ecology Commons, International Public Health Commons, Maternal and Child Health Commons, and the Public Health Education and Promotion Commons How does access to this work benefit you? Let us know!

\section{Recommended Citation}

Leon, Federico R., Carlos Brambila, Marisela de la Cruz, John H. Bratt, Gustavo Gutierrez, Veronica Davila, Carlo Boniato, and Alex Rios. 2004. "Effects of IGSS' job aids-assisted Balanced Counseling Algorithms on quality of care and client outcomes," FRONTIERS Final Report. Washington, DC: Population Council. 


\section{Authors}

Federico R. Leon, Carlos Brambila, Marisela de la Cruz, John H. Bratt, Gustavo Gutierrez, Veronica Davila, Carlo Boniato, and Alex Rios 


\section{Effects of IGSS' Job Aids-Assisted Balanced Counseling Algorithms on Quality of Care and Client Outcomes}

Federico R. León, Carlos Brambila, Marisela de la Cruz, John Bratt, Gustavo Gutiérrez, Verónica Dávila, Carlo Bonatto, Alex Ríos

This study was funded by the U.S. Agency for International Development (USAID) under the terms of Cooperative Agreement Number HRN-A-00-98-00012-00 and In-house project number 8002 13052. The opinions expressed herein are those of the authors and do not necessarily reflect the views of USAID. 


\section{EXECUTIVE SUMMARY}

Context. Very short counseling sessions, counseling not focused on clients' needs, redundancy in the role of physicians and social workers as providers, skewed method mix, and low client return rate for method re-supply prevailed at the main maternity hospital of the Social Security Institute (IGSS) in Guatemala. A need to improve the quality of care was identified.

Methodology. The IGSS adapted the job aids-assisted Balanced Counseling Strategy and developed two service algorithms, one for the social worker and one for the physician. Method cards and method pamphlets were made available to providers. All the providers were trained and received reinforcing revisits during two months. The effects of the intervention were assessed by means of client exit interviews, home follow-up of client cohorts, analysis of service statistics, and a time-motion study.

Results. The intervention changed the counseling behavior of physicians and social workers and enhanced the quality of family planning care. Client choices did not support the hypothesis that improvements in the quality of care would cause a decreased share of the injectable in the method mix. Three decreasing trends in the 19-week preintervention (choice of the injectable, client's reception of her desired method, client knowledge concerning the method chosen) presented reversals in the 19-week postintervention. However, these changes could be attributed to either the intervention, trends in the provider workload, and/or instrumentation bias. Continuation in the use of family planning diminished from month one to month six, particularly in the case of the pill, but the behavior of pre- and post-intervention client cohorts were undistinguishable.

Conclusions. The IGSS should continue using the job aids-assisted Balanced Counseling Algorithms, yet adjustments in instructions concerning post-choice counseling could be introduced and tested to improve client outcomes. The skewed method mix at the IGSS reflects clients' perception of the benefits of the injectable rather than provider bias; hence, the IGSS must adapt to this situation rather than attempting to change it. The sixmonth post-choice contraceptive behavior on the part of an overwhelming majority of 
clients (users of the injectable or the IUD) is satisfactory and may not be amenable to further improvement. Users of pills or condoms require special study and treatment. 


\section{ACKNOWLEDGEMENTS}

The authors are indebted to Irma Ramos for her assistance in the initial workshop of this project and Mario Aldana, Raúl Rosal, and Marco Vinicio González for supporting and helping coordinate the intervention; Karina Arriaza, Nineth Cameros, and Bertha Taracena for their participation in the training of trainers; and Martha Silva and Ingeborg García for helping in the initial data analysis. The cooperation from other health authorities and providers of the IGSS' Gineco-Obstetric Hospital in Guatemala City is gratefully acknowledged. We also thank the supervisors, interviewers, and administrative staff of the Population Council in Guatemala who helped implement the study. 


\section{CONTENTS}

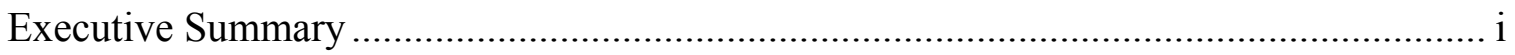

Acknowledgements ......................................................................................... ii

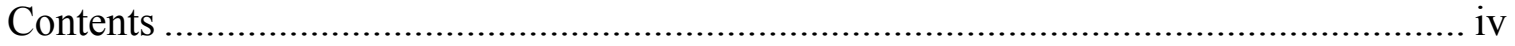

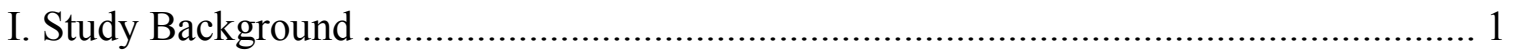

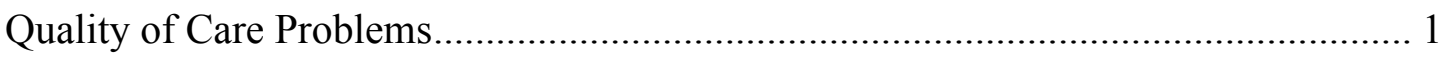

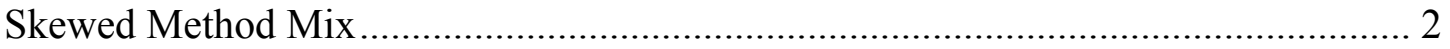

Discontinuation of Family Planning ……………………………………………... 3

Study Objectives and Hypotheses......................................................................... 3

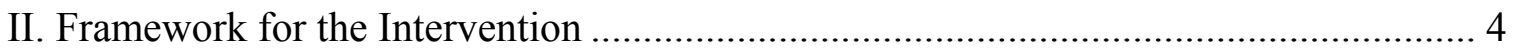

The Job Aids-Assisted Balanced Counseling Strategy.............................................. 4

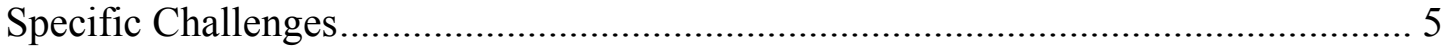

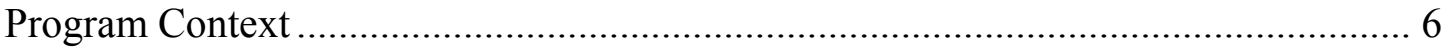

III. Design and Conduct of the Study ………………............................................... 7

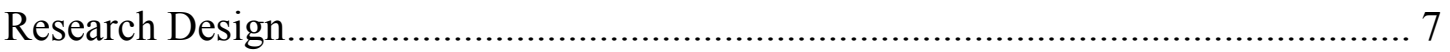

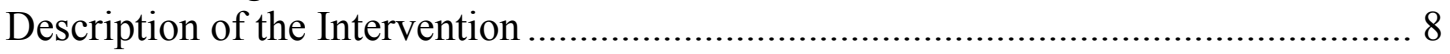

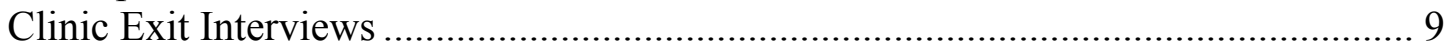

Measures of Quality of Care and Client Knowledge ………………......................... 10

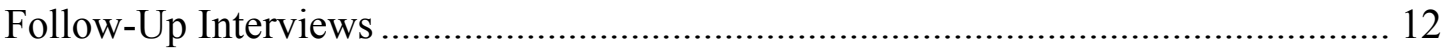

Client Load and Method Mix............................................................................. 13

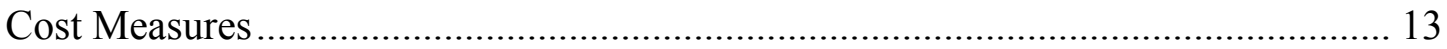

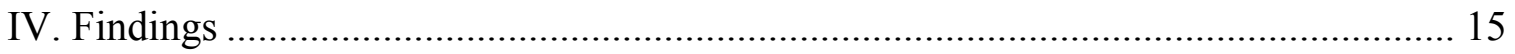

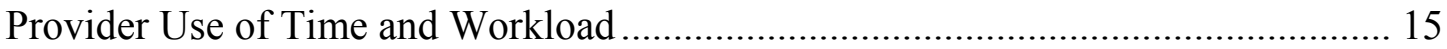

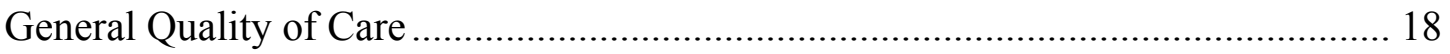

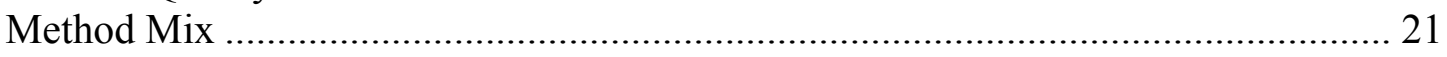

Physician Post-Choice Behavior ............................................................................ 24

Client Knowledge Concerning the Method Chosen .................................................. 27

Use Rates and Continuation in Family Planning ................................................... 32

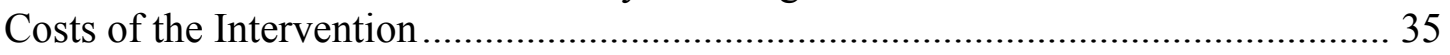

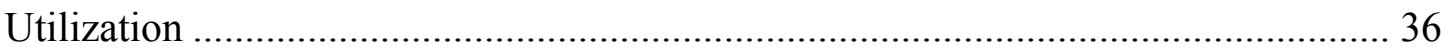

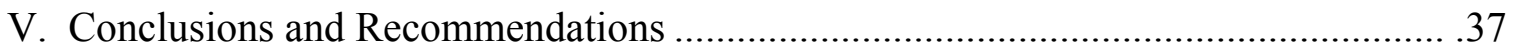

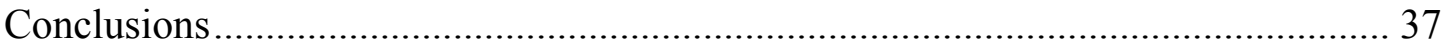

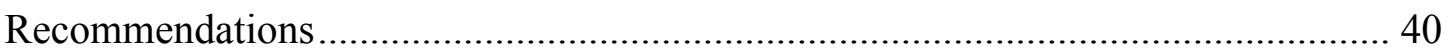

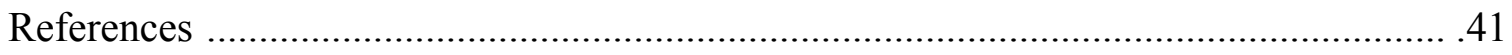

Appendix 1. Balanced Counseling Algorithm for Social Workers .................................... ..

Appendix 2. Balanced Counseling Algorithm for Physicians ............................................ .

Appendix 3. Cards and Pamphlets for Clients ................................................................

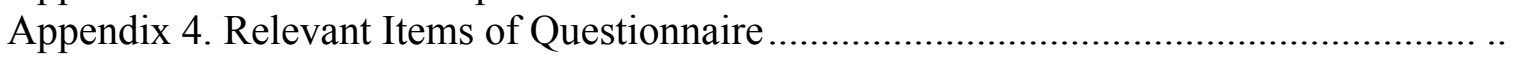

Appendix 5. Calendar Module 


\section{STUDY BACKGROUND}

The Guatemalan Institute of Social Security (IGSS) offers family planning services to its affiliates in connection with obstetric events. It does so through 12 hospitals and 25 outpatient clinics in departments throughout Guatemala. While the IGSS only contributes 4.6 percent of the national prevalence of modern methods, it accounts for 20.8 percent of new DMPA users and 20.7 percent of new IUD users in the general Guatemalan population.

Within the IGSS, the main provider is the Gineco-Obstetrics Hospital located in Guatemala City, which provides services to the metropolitan population in addition to referrals from neighboring municipalities. This hospital hosts the IGSS' Family Planning Program and provides technical leadership to the other IGSS facilities. The hospital offers family planning services to pregnant and puerperal women as well as to postabortion women. Out of nearly 15,000 women who underwent an obstetric event in 2000 at the hospital, more than 12,000 became users of contraception.

Family planning counseling is provided at several stages. Educators offer general family planning information to women who come for antenatal check-ups at least once during their pregnancy. Social workers provide group counseling to antenatal clients and to postpartum and postabortion women before discharge. Individual counseling takes place at the return visit to the Postpartum/Postabortion Clinic after discharge: 30 days (postpartum) or 10 days (post-abortion) after discharge. Women who are affiliates receive services at any time.

Individual counseling is given in two stages at the clinic. The woman is received by a social worker in a family planning session that generally concludes with the client making a preliminary selection of a method. Then the woman is received by a physician who evaluates her obstetrically and revises her family planning status. At this point, some women change their initial decision and leave the clinic with a different method.

\section{Quality of Care Problems}

Several quality of care problems were detected at the beginning of this study. First, given the considerable patient load, the social worker seldom spent more than four 
or five minutes with a client, and each physician saw 25 to 30 clients in the morning shift. Second, the social workers heavily relied on a flipchart that included anatomical figures and four or five descriptors per method to help the client choose a contraceptive. The flipchart was incomplete (failed to include all the methods offered or planned to be offered), was not exhaustive (for instance, did not refer to the temporary infertility that follows discontinuation of DMPA), offered information that was too technical (e.g., method effectiveness rates), and lacked flexibility of use (e.g., did not facilitate comparisons between methods). Third, the physicians paid more attention to contraindications, yet much of their work was redundant with the counseling provided by the social worker. There was a need for standardizing the counseling procedures so as to avoid redundancy and ensure better informed choice.

Finally, the client aids were deficient. A pamphlet to be taken home was needed to compensate for the limited information given by the providers during the counseling and the information-processing limitations of the clients. The pamphlets for clients that were distributed at the IGSS facilities did not satisfy the client's need to count on a memory refresher at home. The IGSS generally offered a general-purpose multi-method pamphlet lacking detailed information. Even its specific pamphlets concerning sterilization, IUD, and implants lacked the detailed information that the client would need as a complement to the oral information received during counseling. Pamphlets concerning the rhythm method, lactational amenorrhea, DMPA, OCs, and the condom were nonexistent.

\section{Skewed Method Mix}

DMPA had been introduced relatively recently at the IGSS, and its growth over the past few years at the hospital had been spectacular. From March through August 2000, the Postpartum/Postabortion Clinic registered 3,207 new DMPA users, i.e., far many more than new condom users (979) or users of tubal ligation (678), IUD (540), OCs (421), or implants (337). The Family Planning Program had two hypotheses to account for this method mix. One considered the method's intrinsic advantages, basically DMPA's ease of use and privacy. The second hypothesis entailed provider bias. Given that DMPA is easier to administer than other reversible methods (fewer side effects, fewer contraindications, simpler use instructions), providers might be favoring it in counseling. 


\section{Discontinuation of Family Planning}

The hospital's Postpartum/Postabortion Clinic did not maintain service statistics for family planning return visits for purposes of follow up. Nevertheless, providers were under the impression that many new users, especially DMPA and condom users, failed to return for re-supply. The question that the IGSS could not answer was whether these patients were obtaining supplies elsewhere, were shifting methods, or were abandoning family planning despite needing it.

DMPA was the most popular method among the clients of the Postpartum/ Postabortion Clinic. The 12-month discontinuation rate for DMPA in the general Guatemalan population was 56.0 per 100 users and the main reasons for discontinuation were side effects (33.0) and method failure (4.0) (DHS/Guatemala, 1999). These reasons are considered to be related to the quality of care received (Jain, 1989; Blanc et al.,1999). The discontinuation rate for the condom was even greater: 68.9 (DHS/Guatemala, 1999).

\section{Study Objectives and Hypotheses}

- Develop job aids-assisted Balanced Counseling Algorithms for physicians and social workers of the hospital.

- Test the effectiveness and assess the cost of introducing the job aids-assisted Balanced Counseling Algorithms at the Hospital.

- Hypothesis 1. Introduction of the algorithms will cause a significant enhancement of the quality of care.

- Hypothesis 2. Introduction of the algorithms will cause a significant reduction of the share of the injectable in the method mix.

- Hypothesis 3. Introduction of the algorithms will cause a significant improvement in client knowledge concerning the method chosen.

- Hypothesis 4. Introduction of the algorithms will cause a significant increase of family planning continuation rates.

- Hypothesis 5. The cost of the intervention will fall within affordable limits. 


\section{FRAMEWORK FOR THE INTERVENTION}

\section{The Job Aids-Assisted Balanced Counseling Strategy}

In late 2000, authorities of the Postpartum/Postabortion Clinic learned that the Peru MOH was successfully introducing a job aids-assisted Balanced Counseling Strategy that seemed to offer significant promise for the solution of the delivery problems identified (see Figure 1).

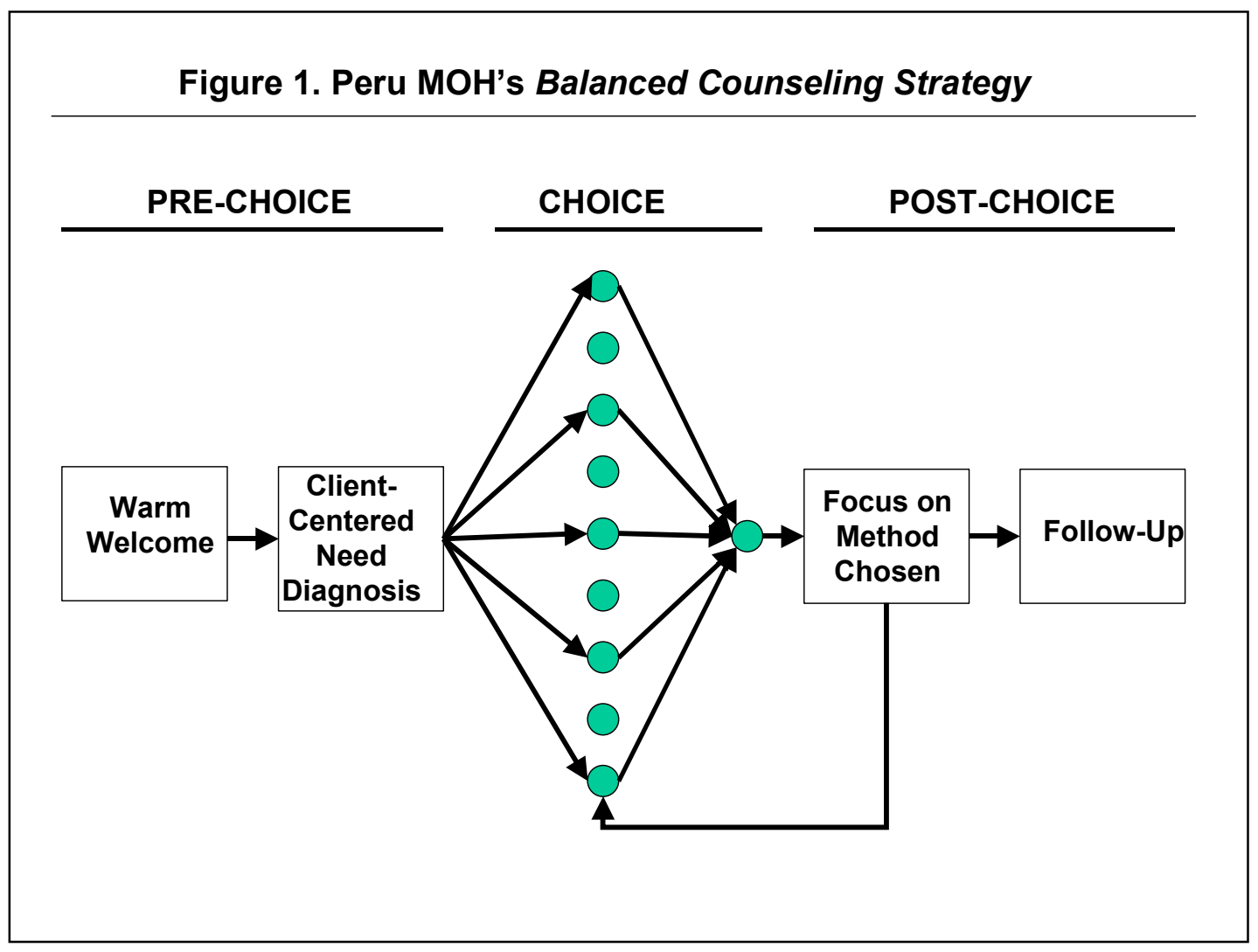

In the pre-choice phase of the new counseling paradigm, the provider interacting with the client - is expected to put client need diagnosis at the center of method choice by publicly discarding irrelevant methods, e.g., tubal ligation and vasectomy if the client is a spacer or barrier, and natural methods if the client's partner does not cooperate in family planning. In the choice phase, the provider avoids client information-overload by limiting the offer of information to four standard descriptors per reasonable method option. The post-choice phase is entirely dedicated to the method 
chosen by the client. If the method is contraindicated for her or if she rejects her preliminary choice once she learns more details about the method (e.g. all the use requirements), the client can go back to the choice phase and choose an alternative method. In every case, follow-up instructions must be given so that the client knows all that is needed to proceed safely and ensure continuity in method use.

The Peru MOH used three job aids to help providers and clients in this process. One was a poster presenting the new counseling model and offering guidance to the provider step by step. The second was a set of 11 small cards, one per method. The cards have on one side the name of the method and a relevant figure and, on the back, four basic descriptors plus a numeral referring to the method's efficacy rate. The provider is expected to display the method cards on the table and discard the irrelevant methods one by one on the basis of the diagnosis of the client's needs. Once a method is discarded, the provider separates the card and tells the client why that method will not be discussed further. At the end of the need diagnosis phase, a number of remaining method cards should lie on the table. The provider reads to the client the four attributes of the surviving methods (or lets her to read them) and asks the client to make a choice.

The third Peruvian job aid was a set of eleven pamphlets, one per method. The four-page pamphlets have sections concerned with general method characteristics and the method's contraindications, action mechanisms and benefits, use instructions, side effects, alarm signs, and follow-up instructions. The provider tells the client, "Ma'am, you are going to take this pamphlet home, but now I want to explain its contents to you", and then uses the pamphlet as a checklist to screen the client for contraindications and to offer detailed information on the method chosen. The client is not expected to perceive the pamphlet as a job aid for the provider but as an aid for herself (León et al., 2002).

\section{Specific Challenges}

The IGSS decided to adapt the job-aids assisted Balanced Counseling Strategy to improve the quality of care, reduce the discontinuation of family planning, and eventually reshape the contraceptive method mix maintaining the costs of service delivery under manageable proportions. Three major challenges were faced. 
Whereas in Peru the provider typically was a professional obstetric nurse with university education, a majority of the Postpartum/Postabortion Clinic providers were social workers without a university background in reproductive health. The question arose whether the latter would be able to implement the Strategy on the basis of its spare general instructions or more detailed guidance was needed. Responding to these concerns, an algorithm that offered more detailed guidance to the provider was proposed.

The second issue was the redundancy between the roles of the social worker and the physician in serving the same client. This could be solved by further differentiating the tasks of the two professionals by means of two non-redundant algorithms: one for the social worker and one for the physician.

In Peru the intervention had substantially improved the quality of care, but only a minority of the trained providers actually implemented the Strategy in their interactions with clients. This was attributed to the shortness of training and weaknesses in the implementation of the reinforcement component of the model. To strengthen the motivation of providers to use the innovation in their interactions with clients, the IGSS would have to place special emphasis on the reinforcement of learning through supervision.

\section{Program Context}

The Postpartum/Postabortion Clinic provides family planning services to more than 1,000 new users per month who have recently undergone an obstetric event. Other family planning clients (women in the interval between pregnancies) also receive family planning counseling and methods at the hospital's outpatient services. Twelve social workers take care of the counseling needs of all these family planning clients, yet they have to distribute their time among family planning and a number of other tasks. Only two social workers are entirely dedicated to family planning counseling in the morning shift. Similarly, while about 10 physicians are connected to family planning in various functions (e.g. performing tubal ligations or vasectomies, inserting IUDs), only two provide counseling to new users in the entire day. Other staff in some way related to family planning services include 5 educators and 5 nurses. 


\section{DESIGN AND CONDUCT OF THE STUDY}

\section{RESEARCH DESIGN}

Figure 2 depicts the research activities that were conducted. The effects of the Job Aids-Assisted Balanced Counseling Algorithms on quality of care and client knowledge were assessed by means of client exit interviews that started at month 11 (late August 2001) and ended at month 20 (May 2002) and encompassed 19 weeks before the intervention, 2 weeks of provider training, 8 weeks of reinforcement, and 9 weeks after the intervention. The dark column of Figure 2 (month 16, January 2002) includes the two weeks of provider training plus one week before and one week after the training. The reinforcement activities ended in month 18 .

To assess the impact of the intervention on client flow and method mix, the timeseries was extended and encompassed nine quarters of service statistics. The effects on discontinuation were evaluated by means of a cohort design that compared (a) a 15-week client cohort recruited before the training of providers and followed-up 8.5 months later on average with (b) a 13-week client cohort recruited after the training and followed-up 7.5 months later on average.

Figure 2. Design of Research Activities

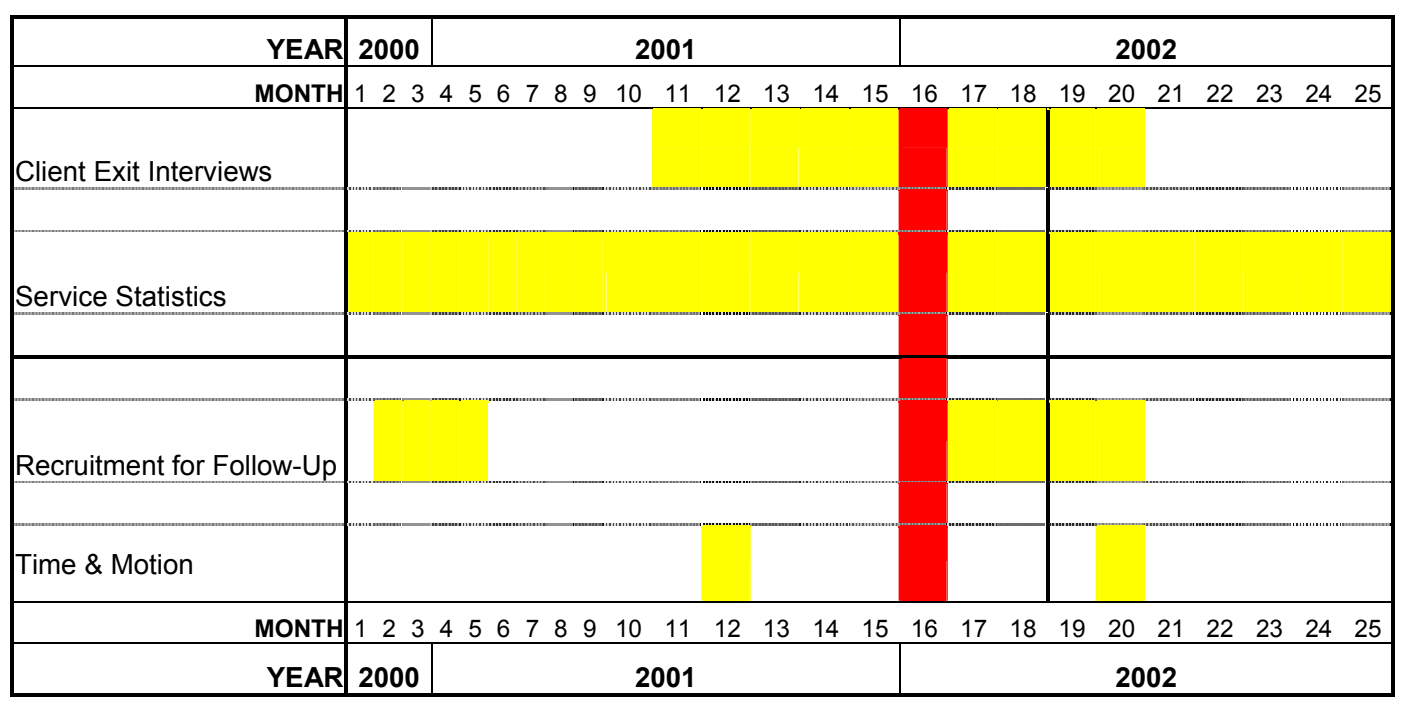


The effects of the intervention on economic outcomes were assessed by means of a four-week time and motion study of provider behavior that took place 14 weeks before the training and was repeated 13 weeks after the training.

\section{Description of the Intervention}

Algorithms and Method Cards. A working meeting was convened at the Postpartum/Postabortion Clinic on September 16-18, 2001. IGSS technical authorities (4 physicians and 3 social workers) and Council staff and consultants from Peru and Guatemala participated in it. The Balanced Counseling Strategy was described in detail and discussed at this meeting. The proposed Algorithm was adjusted and yielded two versions aimed at reducing redundancy, one for the social worker and the other for the physician (see Appendices 1 and 2). The linkage between the two algorithms was the Social Data Sheet that the client carried from the first to the second counseling session. The social worker was expected to write down the method chosen by the client on her Social Data Sheet and the physician was expected to receive the sheet from the client and start counseling her with knowledge of the method chosen. Eight method cards and one to discard pregnancy were designed taking into account the IGSS norms. These were somewhat larger than the cards used in Peru $(11.7 \mathrm{~cm}$ [width] by $8.5 \mathrm{~cm}$ [height]) and one side presented the method, its four descriptors, and its effectiveness rate while the back presented its contraindications. (see Appendix 3A.)

Method Pamphlets. The method pamphlets used were produced by the USAIDsponsored Calidad en Salud Program, that had recently designed tools adjusted to the educational and cultural requirements of the users. The pamphlets entailed the necklaceassisted rhythm method, Billings, lactational amenorrhea, condom, pills, injectables, IUDs, tubal ligation, and vasectomy. Lacking was a pamphlet concerning implants. The main differences with the Peruvian pamphlets were the size $(12.4$ by $19.3 \mathrm{~cm})$, the inclusion of human and anatomical figures, the exclusion of contraindications, and a generally smaller number of informational items. The contents of cards and pamphlets were consistent with the IGSS's Norms of the Family Planning Program (Appendix 3B shows an example of the pamphlets). 
Training of Providers. This phase started when the Calidad en Salud method pamphlets were made available to the IGSS in January 2002. Each of 20 providers (5 physicians, 10 social workers, 2 nurses, 3 educators) received eight hours of group training divided into two sessions on contiguous days. The training was replicated across three groups of seven and was provided by 3 IGSS staff, 2 Council staff, and 2 from Calidad en Salud. The former five were in charge of the algorithms and method cards, while the latter two presented the method pamphlets. A counseling manual was distributed to all the providers. Three of the eight hours were dedicated to role-playing.

Monitoring and Reinforcement. The eight hours employed in provider training were only the first step of a learning program. In the following eight weeks, each provider was monitored at least twice a week while he/she was counseling clients. The retraining team, formed by the project coordinator and one assistant, observed service provision using a checklist and gave feedback to the provider as soon as the client left. Three or four service interactions were observed in each visit to a provider.

\section{Clinic Exit Interviews}

Interviewer Training and Supervision. All the interviewers were female. They were recruited among professionals with experience conducting surveys. None had had a prior work with the IGSS. The project coordinator trained them in the use of the questionnaire to be used in exit interviews. The data collection started in late August 2001 and ended in early May 2002. Supervision of their work was daily.

Informed Consent and Inclusion Criteria. Informed consent to be interviewed was requested from the clients as they exited the consultation at the Clinic. Postpartum women coming to their first consultation 30 days after the obstetric event and postabortion women coming to their first consultation 10 days after the event were considered. A third group consisted of women who had not recently undergone an obstetric event. The inclusion criterion for the three groups was that they had chosen a family planning method in the consultation.

Interview Process. In the weeks of data collection, between two and four interviewers stayed at the Clinic during the two entire shifts of each working day. In 
the first days of the pre-intervention, they interviewed as many clients as they could that exited their second counseling session. Later on, a daily quota was sought. The interviews were carried out with the clients that agreed to participate. The questionnaire items were formulated prior to the production of method cards and pamphlets (see Appendix 3). 2,147 clinic exit interviews were completed in the pre-intervention (19 weeks, from August 27, 2001 through January 4, 2002) and 2,142 in the post-intervention (19 weeks, from January 7 through May 13, 2002), i.e., 113 per week on average. Of these, 67 percent represented postpartum cases, 10 percent postabortion cases, and 23 percent interval cases. The clients were seen by both a physician and social worker in 74 percent of the cases and by the physician alone in 26 percent of the cases. Of the total sample, 56 percent had chosen the injectable, 23 percent the condom, 13 percent the pill, 9 percent the IUD, and 4 percent other methods. To test the study hypotheses pertaining to improvements of quality of care and client outcomes, each indicator obtained from the client exit interviews during a given week was averaged over all clients during the week. Thirty-eight such weekly averages were analyzed.

\section{Measures of Quality of Care and Client Knowledge}

The questionnaire contained three types of items relevant to the hypotheses of the study: 1. client's attributions of provider information-exchange pertaining to need diagnosis, method choice, and client discharge; 2. client's spontaneous recall concerning information on the method chosen; and 3. client's attributions of provider informationexchange pertaining to the method chosen. The method chosen was defined as the method chosen during the consultation, regardless of whether the client received it the same day or not. Whereas in most cases the method chosen and the method received coincided, in several instances they did not. For example, the client could have chosen the IUD and been given condoms for use until she met the requirements for an insertion. In these cases, the interviewer asked the client about both methods.

General Quality of Care. Eleven items were included in the measure of general quality of care (see Appendix 4A). Six of them entailed data gathering (e.g. whether the provider asked about intentions to use family planning, preliminary choice of a method, reproductive intentions, partner's attitude, past use of contraception, or made sure the 
client had understood), five entailed other actions (e.g. whether the provider asked the client to choose a method, supplied a method or made a referral, delivered a method pamphlet), and two entailed client judgments (e.g. how she felt she was treated, whether the information received was sufficient). The items were scored 1 (Yes) or 0 (No) and summed to yield a total score. Care was taken to avoid penalizing the provider when the client already had a method in mind. Since the provider was expected to respect the client's early choice of a method, the "provider asked the client to choose a method" item was automatically scored 1 when the client asked about having a method in mind and the client responded saying that she had already chosen a method.

Spontaneous Recall, Method Chosen. Two types of questions were asked concerning the method chosen (see Appendix 4B). One consisted of open-ended questions such as "How are pills used?" The interviewer had on the questionnaire all the correct responses and marked them if they were spontaneously mentioned by the client. This is a spontaneous recall task that in Peru was found to be positively associated with the intervention. The questions entailed how to use the method, advantages, side effects, danger signs, follow-up, and contraindications. Item scores $(1=$ Mentioned, $0=$ Not mentioned) were summed for all the items pertaining to a method. The ten least ambiguous items concerning the injectable, pill, IUD, and condom were selected for analysis. The smaller numbers of cases for other family planning methods caused data cells for several weeks to be empty and prevented further specific analyses.

Recognition/Attribution, Method Chosen. Once the section concerning recalltype questions was completed, the interviewer formulated recognition-type questions such as "Did the doctor tell you that the IUD insertion only takes a few minutes?" This type of question in the questionnaire differed from the recall task in that the response options were shown to the client and pertained to the physician's behavior. The client just had to answer Yes or No. This type of question applied to all the items for which the client had not supplied a correct spontaneous recall response.

Control Items. To explore possible methodological artifacts as well as the relationship between recall and recognition in the pre-intervention and post-intervention, we used four control items in the questionnaire. These were danger signs of the pill that 
were asked with respect to the injectable despite that the latter does not actually have these danger signs (e.g. breastache, blurred vision).

\section{Follow-Up Interviews}

Recruitment. In the recruitment phases before and after the intervention (see Figure 2), one member of the study team stayed at the Clinic during the two entire shifts of each working day and requested from each client in the waiting room her informed consent to participate in the study. Consent to be followed-up was requested from the clients at the end of the consultation with a provider. The inclusion criteria were similar to those of the clinic exit interview. The clients who agreed were asked to provide detailed contact addresses. Later, the social worker that provided counseling to the client supplied a copy of the Social Data Sheet for that client that included information on the method chosen. About 80 percent of the clients contacted agreed to be interviewed later.

Home Contacts. The clients were followed-up approximately 8.5 months after recruitment in the pre-intervention cohort and 7.7 months in the post-intervention cohort. Over 95 percent of the contacts took place at the client's household and the remainder at the Clinic. The loss to follow-up was 25 percent on average. The most frequent categories were "incorrect address" (14 percent) and "moved from address" (6 percent). The interviewer used the calendar module of the Demographic and Health Survey that asks the client about her present contraceptive use and goes back month by month to reconstruct her family planning history (see Appendix 5).

Use Rate. The use of family planning was evaluated by means of two rates. The use rate was the percentage of clients who, at a given month, were using family planning. The unit of analysis was the individual client. One user who discontinued using a method would count negatively on a given month, yet could re-enter the percentage of users if she re-started use later. For example, the seven-month use rate is the percentage of clients, out of the total number of clients participating, that was using family planning at month seven regardless of their use history in the prior months. The month of recruitment was defined as month one for clients recruited during the first 15 days of the month. The next month was defined as month one when the clients were recruited in the second half of the month. 
Continuation Rate. This rate was obtained from life tables in which the unit of analysis was the segment of use rather than the individual client. A segment of use ends when the client stops using family planning. If she re-initiates use, a new segment is entered into the life table. For example, the seven-month continuation rate was calculated as the percentage of clients that continually used family planning from month one through month seven. The denominator in this rate is not the total number of clients but the total number of use segments. Hence, the continuation rate is always less than the use rate.

\section{Client Load and Method Mix}

Service Statistics. Official IGSS service statistics were employed to evaluate changes in client load. These originated in daily reports by providers and were recorded per month. A new user of a given method was the person who received a method. Women in the interval who chose the IUD or a hormonal method in a consultation and were not ready to receive the method did not count as new users. Natural methods were not considered in the method mix during the pre-intervention period of the study.

Exit Interviews. Weekly data from client exit interviews were analyzed to assess method mix as a complement to the service statistics. A new user of a method was the person who made the decision to use a given method, regardless of whether she received the method at the end of the consultation or was given an appointment to receive it later. Natural methods were included in the assessment of method mix.

Physician Reports. To obtain a specific measurement of provider workload we collected the physicians' daily consultation reports and divided the monthly number of consultations by the monthly number of provider shifts. Comparable data from social workers were not available.

\section{Cost Measures}

The economic analysis was designed with two main purposes in mind: first, to document the incremental cost-effectiveness of the intervention to improve quality of 
care; and second, to provide information to IGSS executives on the costs of replicating the intervention in other areas of the country.

Unit and Total Cost. Three phases of the intervention process were identified: the design phase, which consisted of meetings of project staff to discuss the content of the intervention and to develop and adapt curriculum for the training sessions; the implementation phase, which included the training sessions themselves; and the supervision phase, in which project staff followed providers to assess their performance and provide feedback and reinforcement. Customized spreadsheets were used to collect information on the various inputs (i.e., labor, materials and capital) used in each phase of the intervention. We identified the inputs, measured the quantity of each input used, assigned a unit cost to each input, and calculated total cost by multiplying the quantity used by the unit cost.

Time-Motion Study. Impact of the new counseling strategy on provider allocation of time to different tasks and activities was measured through a provider timemotion study conducted before and after the intervention. All the family planning providers at the clinic were asked for their informed consent to be observed in the timemotion study. Trained observers used the "activity sampling" technique, in which an observation of provider activity is made at three-minute intervals. Separate analyses were carried out for physicians and social workers.

The following five broad categories of provider activity were defined:

- client contact - includes time spent providing counseling or direct patient care;

- non-contact work-related - includes all administrative tasks, consultations with other providers, work-related absences from the clinic, and on-the-job training;

- personal time - includes coffee, lunch and bathroom breaks;

- unallocated time - includes time spent waiting for clients, conversations with staff and/or others that are not related to work, and personal telephone calls;

- absent from clinic - includes time for which the provider is paid, but is absent from the clinic without official permission. 
The time-motion pretest was carried out in September and October 2001, and the posttest was carried out in April-May of 2002. The official length of shifts for IGSS physicians is four hours, and eight hours for IGSS social workers.

\section{FINDINGS}

\section{Provider Use of Time and Workload}

The intervention was expected to leave provider use of time and workload unchanged.

Physicians. Table 1 presents information from the time-motion study on changes in provider time use during the study period. Prior to the intervention, physicians spent an average of 74 minutes per shift in direct contact with clients, which equates to 31 percent of a four-hour shift. After the intervention, average time spent with clients

\section{Table 1. Changes in Average Time Spent on Various Activities per Shift by Physicians and} Social Workers, Postpartum/Postabortion Clinic, IGSS Guatemala

\begin{tabular}{lcccc} 
Category of Time Use - Physicians & \multicolumn{2}{c}{ Pretest $(\mathrm{n}=36)$} & \multicolumn{2}{c}{ Posttest $(\mathrm{n}=42)$} \\
& Minutes & $\%$ & Minutes & $\%$ \\
Direct contact with clients & 74 & 31 & 108 & 45 \\
Administrative time & 74 & 31 & 64 & 27 \\
Personal time & 25 & 10 & 3 & 1 \\
Unallocated time & 6 & 3 & 15 & 6 \\
Absent from clinic during shift & 61 & 25 & 50 & 21 \\
Total & 240 & $100 \%$ & 240 & $100 \%$ \\
Category of Time Use - Social Workers & \multicolumn{2}{c}{ Pretest } & $(\mathrm{n}=32)$ & \multicolumn{2}{c}{ Posttest (n=36) } \\
& Minutes & $\%$ & Minutes & $\%$ \\
Direct contact with clients & 155 & 32 & 153 & 32 \\
Administrative time & 217 & 45 & 226 & 46 \\
Personal time & 66 & 14 & 37 & 8 \\
Unallocated time & 33 & 7 & 32 & 7 \\
Absent from clinic during shift & 9 & 2 & 12 & 3 \\
Observation not permitted & 0 & 0 & 20 & 4 \\
Total & 480 & $100 \%$ & 480 & $100 \%$ \\
\hline
\end{tabular}

increased to 108 minutes per shift, or 45 percent of the shift. It seems reasonable to attribute the increase to the more thorough counseling model that was introduced, 
although an alternative explanation would state that the initiation of the post-intervention coincided with the incorporation of new residents, who could be expected to spend more time with clients until they gained experience. The number of client consultations was similar in the pre-intervention period (2,457 consultations) and the post-intervention period (2,516 consultations), and so higher demand does not explain the difference in physician contact time. Since physicians were spending proportionally more time in contact with clients, time spent in other activities had to decline overall. The largest change is in personal time, which declined from 25 to 3 minutes per shift. But the amount of time spent in non-productive pursuits (e.g. unallocated time, absence from the clinic) scarcely changed. It is possible that when faced with the need to spend more time in client contact, physicians preferred to sacrifice their work breaks rather than their habit of leaving the clinic for other pursuits.

Social Workers. Patterns of time use by social workers did not exhibit the same changes as those seen with physicians. The number of minutes devoted to direct client contact remained nearly the same over the study period, and the overall proportion of time spent in work-related activities only increased by one percentage point, from 77 to 78 percent. Non-productive time also was nearly unchanged. The only difference observed was a decline in personal time, from an average of 66 minutes per eight-hour shift in the pretest to 37 minutes per shift in the posttest. This decline was largely offset by the appearance in the posttest of a new category, "observation not permitted," which includes the time that observers were refused access to service providers (mainly during approved workbreaks).

Workload. Whereas the time-motion study found that essentially similar numbers of consultations were registered in September-October $2001(\mathrm{~N}=2,457)$ and April-May $2002(\mathrm{~N}=2,516)$, the IGSS service statistics (see Figure 3) showed that a substantially greater number of new family planning users were served in the first than in the second pair of months. Moreover, the trend specified by a linear regression line (i.e. that in the pre-intervention is positive and of marked slope, while in the post-intervention is negative and less steep) suggests that the intervention caused a sharp decline in the number of family planning users. 
Figure 3. Time Series for Number of New Method Users in Pre- and Post-Intervention, from IGSS Service Statistics

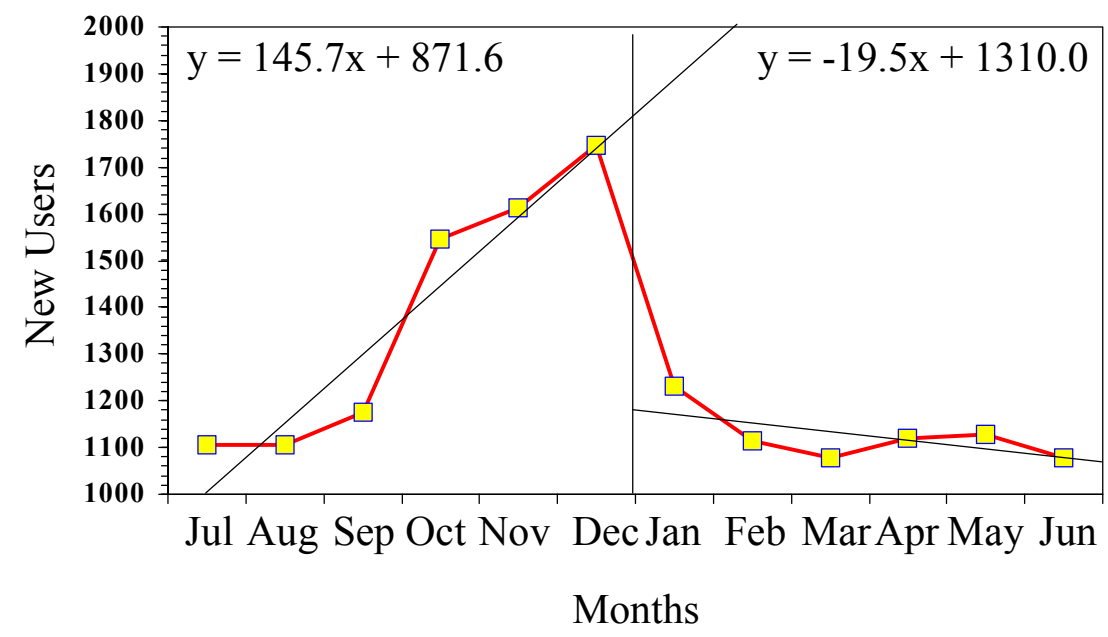

To gain further insights into the discrepancy between the time-motion study and the IGSS service statistics we examined the ratio of monthly number of consultations by physicians to the monthly number of physicians' shifts. Figure 4 presents the monthly time series for this indicator of provider workload. The curve suggests a slightly

Figure 4. Number of Consultations per Shift in Pre- and PostIntervention According to Physician Daily Reports

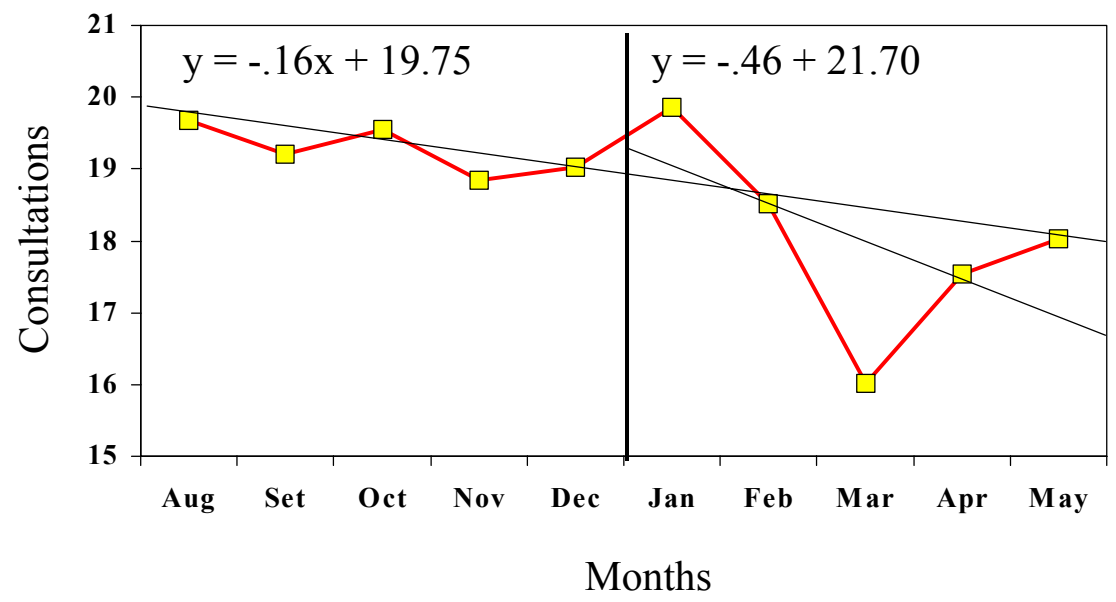


decaying working effort by the providers that becomes more marked from January to March 2002 and is followed by a recovery in April and May.

Intervention or Seasonality? In summary, according to the time-motion study, similar numbers of consultations were delivered by providers in the pre- and postintervention periods of the study. According to the bureaucratic figures, however, new family planning method users and number of consultations per provider shift diminished in the post-intervention. These figures, however, may just reflect a seasonal trend in reporting. This hypothesis is supported by two findings. First, the number of new method users showed a dramatic peak in December 2000 and then a return to normal in January 2001 (Aldana \& Rosal, 2002). Second, in January-May 2002 the number of new method users was roughly similar to the equivalent months of 2001 (Bonatto, 2003). Hence,

a) a tendency to report increased workload at the end of the year explains the prepost-intervention changes observed in the bureaucratic indicators and

b) the time motion-study suggests that the intervention did not cause changes in the number of clients seen by providers.

\section{General Quality of Care}

The quality of care was hypothesized to improve following the intervention.

Trends in Pre- and Post-Intervention Periods. Figure 5 depicts the 38-week time series for general quality of care from client exit interviews, i.e., the sum of 11 item scores pertaining to provider's data gathering and other actions at various points in the consultation. None of the slopes showed a growth trend (the $b$ coefficients approached zero) but there was a difference in altitude between the series that the figure highlights via projection of the pre-intervention trend onto the post-intervention space $\left(a_{\text {pre }}=7.66\right.$, $\left.a_{\text {post }}=8.58\right)$. The difference in general quality of care scores between the pre- and postintervention was statistically significant $(t=11.1, p<.000$, one-tailed).

A majority of clients received dual services, i.e., from both the physician and the social worker. Figure 6 presents the time series for these cases as well as those that were seen only by a physician. Just on a few dates were clients seen only by a social worker. The probability that the dual service scores were above those for the physician 
alone because of random variation is below $p=.00$, two-tailed. Clearly, the social workers made an important contribution both to the quality of care and its improvement.

Figure 5. Time Series for General Quality of Care in PreIntervention (weeks 1-19) and Post-Intervention (weeks 20-38)

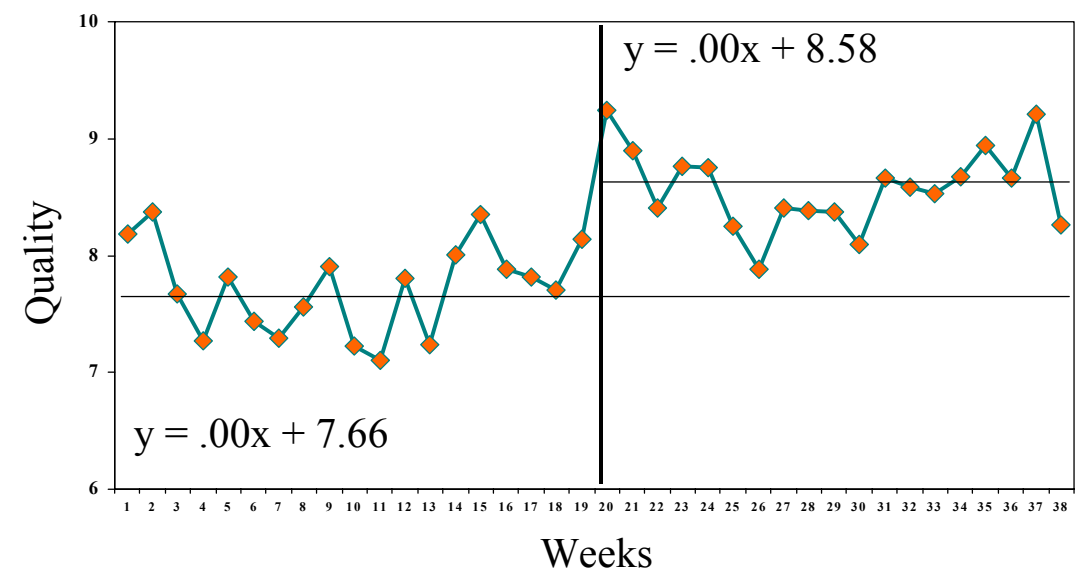

Figure 6. Quality per Provider: Physician (continuous orange line), Social Worker (black dot), or Both (discontinuous green line)

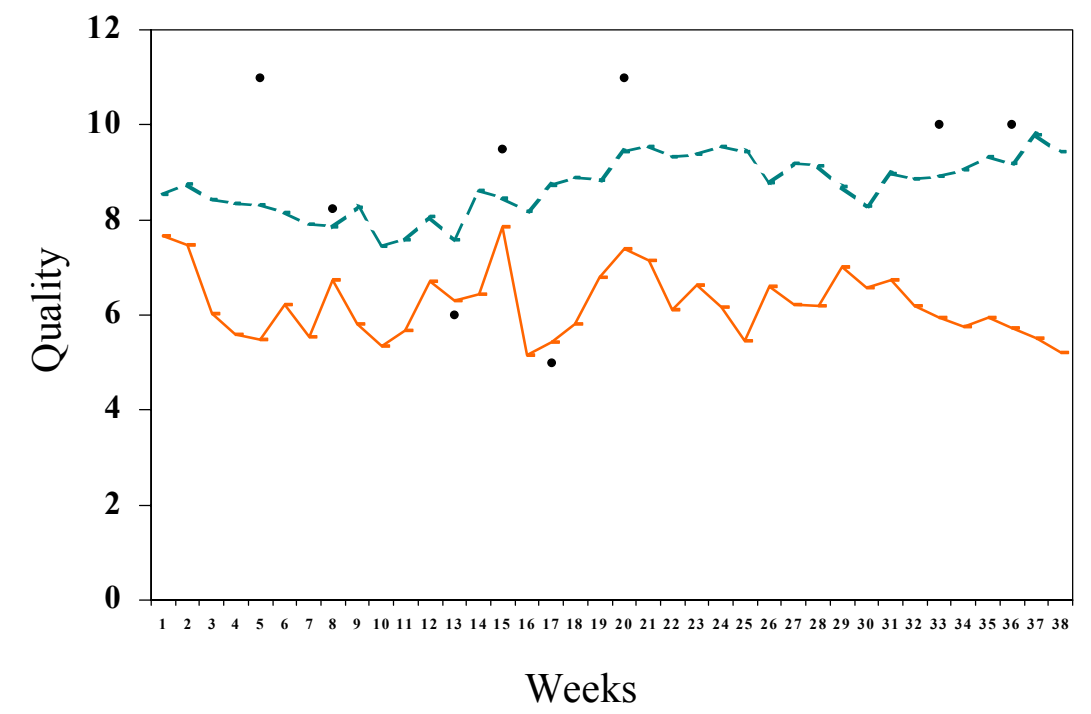


Method Already Chosen. Another way of looking at the quality of care is determining whether the client is allowed to fulfill her choice of method. An item of the questionnaire asked, "Did you or did you not have a method already chosen at the beginning of the consultation? Which one?" The interviewers were instructed to make clear to the client that they were referring to initiation of the family planning consultation at the hospital that day, not to the specific consultation with the physician. Eighty-six percent of the clients said that they had already chosen a method at the beginning of their consultations. This is not surprising since all the postpartum and postabortion clients had received prior group counseling. Figure 7 shows the time series for the percentage of clients who received (or were given an appointment to receive) the method chosen at the beginning of the consultation. Fulfillment of the client's early choice decreased steadily during the pre-intervention but increased along with the improvement of the general quality of care scores in the post-intervention.

Figure 7. Percentage of Clients Who Received the Method* that

They Had Already Chosen at the Beginning of Consultation

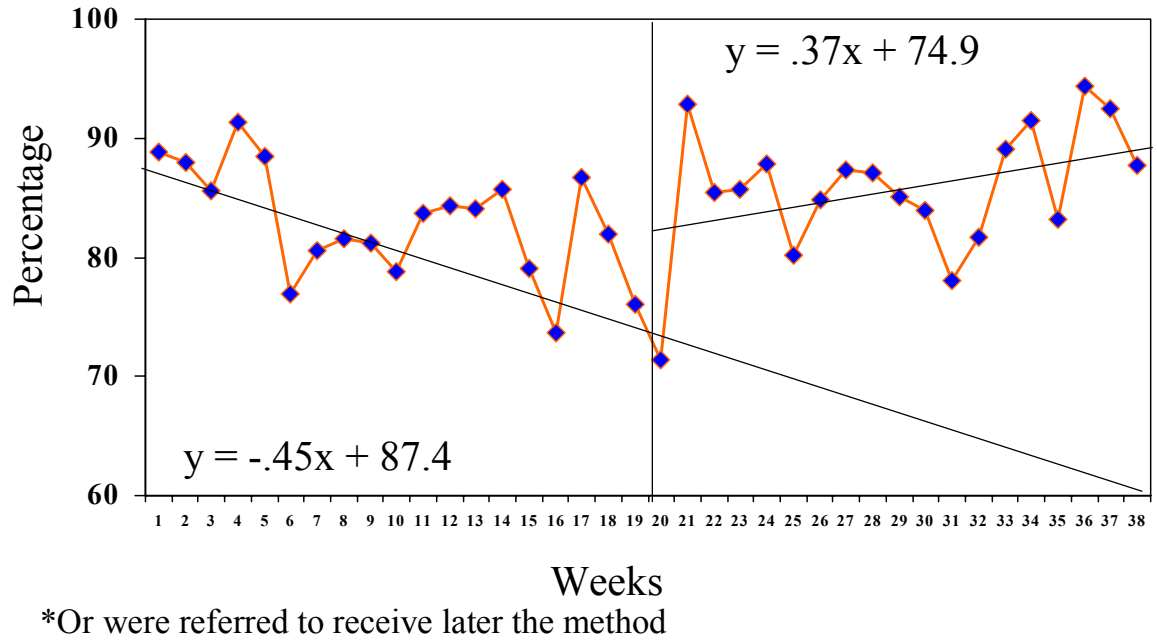




\section{Method Mix}

The share of the injectable in the method mix was hypothesized to decrease following improvements in the quality of care.

Choice of the Injectable. Share in method mix was measured by the percentage of users of a given method with respect to the total number of clients who received a method or an appointment to receive it in the future. In 65 cases of the clinic exit interview, the client received the condom as a temporary method, in addition to receiving an appointment for an injection or the insertion of an IUD. These women were classified as users of the temporary method. Similar was the case when the client received pills or the injectable while she waited for sterilization. The time series for the share of the injectable in the method mix (see Figure 8) shows a downhill trend in the pre-intervention that is reversed and becomes positive during the post-intervention. Hence, contradicting the hypothesis of the study pertaining to method mix, these results showed that the enhancement of the quality of care that took place from week 20 came with increased odds that clients received the injectable, and suggest that the historic growth of this method at the hospital reflected client preferences rather than provider bias.

Figure 8. Time Series for Share of New Injectable Users in Method Mix, Pre/Post-Intervention, Exit Interviews

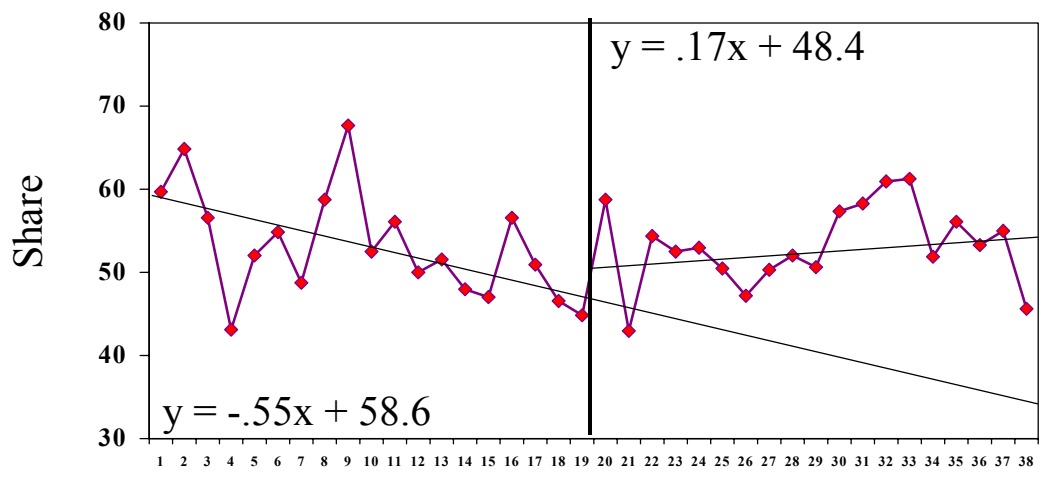

Weeks 
Choice of Pill, IUD, and Condom. Whereas 62 users of the injectable were counted per week on average, the sample sizes for the other methods were too small to guarantee the series' reliability: $n=9.9$ for the IUD, $n=14.1$ for the pill, and $n=25.9$ for the condom. Even smaller sizes corresponded to other contraceptives. To protect the reliability of the observations, and for the sake of parsimony, we decided to integrate users of the pill, IUD, and condom in all further analyses. For the method-mix share of the three targeted methods, Figure 9 shows an ascending series in the pre-intervention that reverses its slope and becomes negative in the post-intervention. As the choice of the

Figure 9. Time Series for Share of New Pill, IUD, or Condom Users in Method Mix, Pre/Post-Intervention, Exit Interviews

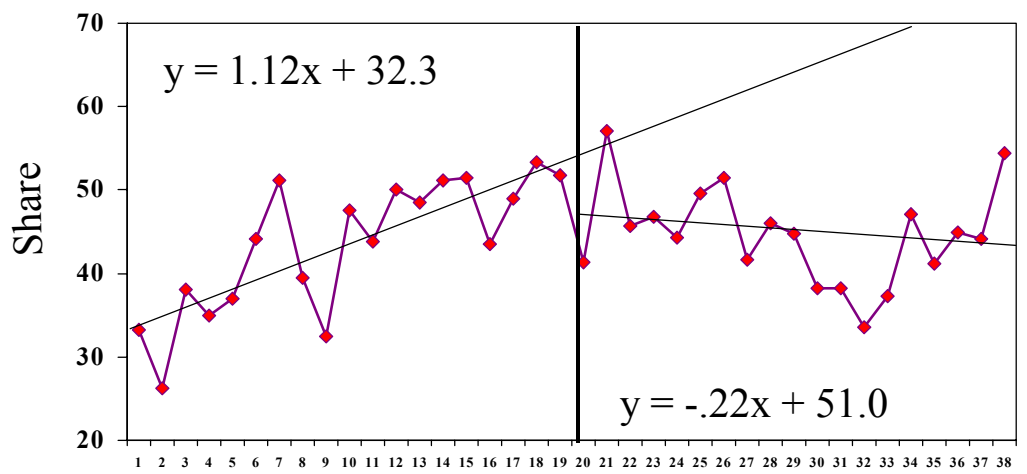

Weeks

injectable shrank in the pre-intervention, other method options increased their odds of being chosen. Contrariwise, the enhanced quality of care that brought with it an increased choice of the injectable in the post-intervention left a more limited space for the choice of pill, IUD, or condom.

Role of the Quality of Care. To more specifically delineate the role of the quality of care in these processes, we targeted the level of quality of care given to clients who had different methods in mind at the beginning of the consultation. Both in the case of clients who had already chosen the injectable and in the case of clients who had chosen 
the pill, IUD, or condom, the curves in Figure 10 show a jump from pre- to postintervention. On the other hand, the graph shows that a consistently greater general level of quality of care was offered to clients who had chosen the injectable. This trend was expressed in the pre-intervention as well as in the post-intervention. This suggests that providers benefited from their greater practice delivering the injectable given the larger demand for this method.

Figure 10. Quality of Care Given to Users Who Had the Injectable (blue discontinuous line) or Other Methods* in Mind (orange continuous line)

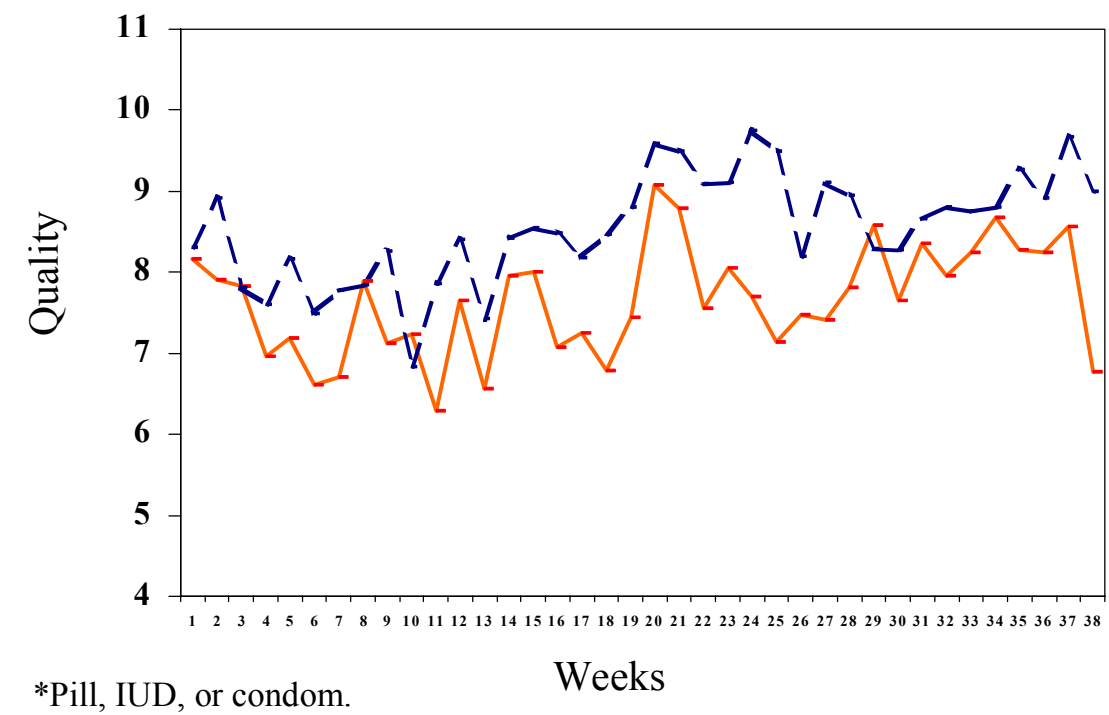

Service Statistics. The IGSS service statistics yielded different results. As shown in Figure 11, the pre-intervention series for the injectable was moderately positive and maintained its slope during the post-intervention. According to these results, the injectable only continued to increase its share in the method mix in the post-intervention. Thus the service statistics (Figure 11) contradicted the client exit interviews (Figure 8) insofar as the share of the injectable in the method mix is concerned. The inconsistency can be attributed to several factors. First, in the case of interview data, natural methods were considered in both periods. Yet the service statistics did not include natural methods in the pre-intervention; hence, these methods were also excluded from the postintervention database. Second, the new user of a family planning method according to the interviews was a woman who either physically received the method or was given an 
appointment to receive it later. The new user according to the service statistics included only the woman who received the primary method during the consultation. For example, if a client chose the IUD, was given an appointment for the insertion, and received condoms as a temporary method, she was not counted as a new user of either method in the service statistics. Third, the IGSS service statistics were generally inconsistent with other data in this study.

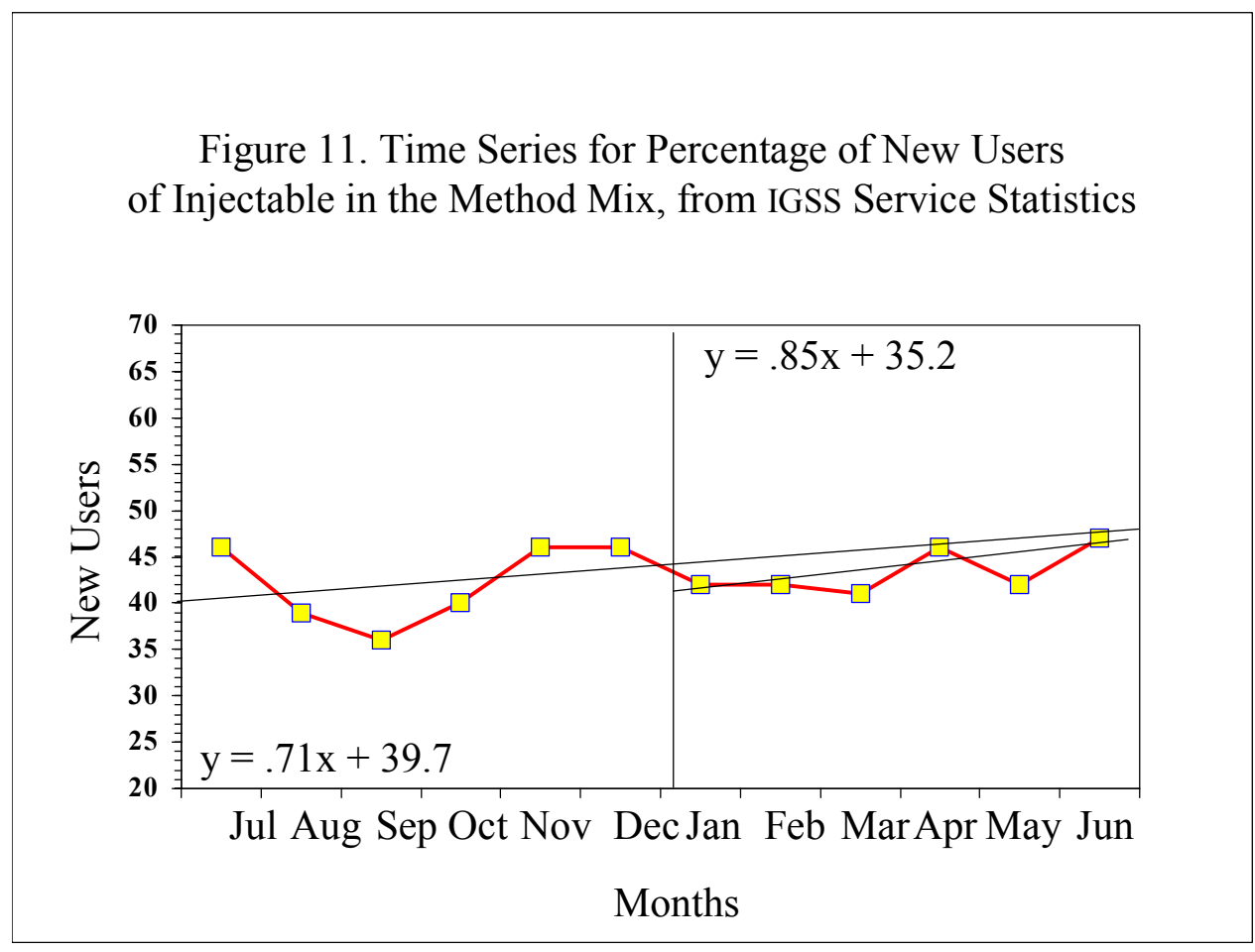

\section{Physician Post-Choice Behavior}

The intervention was hypothesized to enhance the provider's counseling behavior focused on the method chosen by the client.

Information-Exchange on Method Chosen. Figures 12 and 13 present the time series for physician information-exchange behavior concerning the method chosen (The questionnaire did not include similar questions about the social worker). The scores correspond to the sum of Yes-responses when the clients were asked whether the physician had shown specific counseling behaviors pertaining to the method chosen 
Figure 12. Time Series for Physician Information-Exchange

Concerning the Injectable in Pre- and Post-Intervention

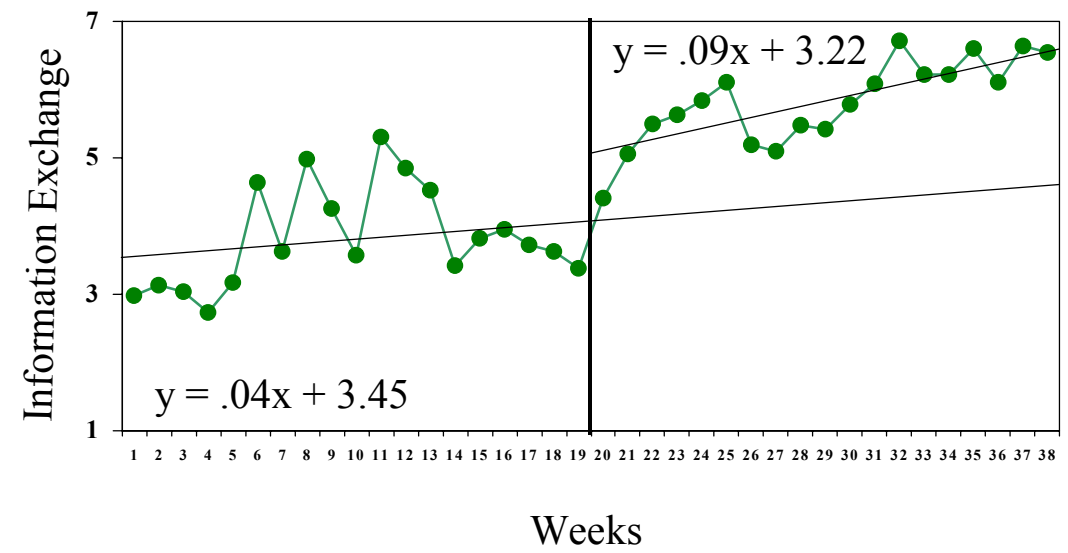

Figure 13. Time Series for Physician Information-Exchange Concerning the Pill, IUD, or Condom, Pre-Post-Intervention

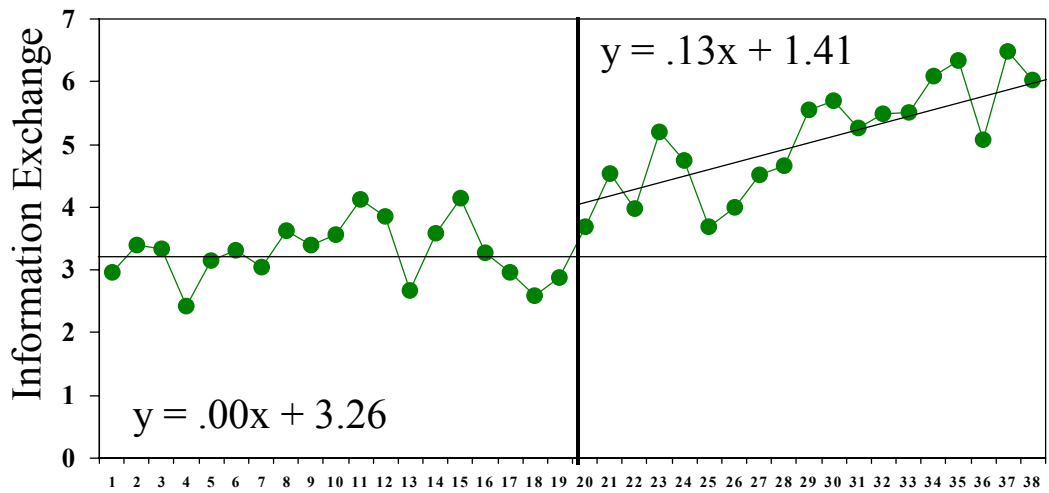

Weeks

(e.g. items entailing use instructions, screening for contraindications, side effects). More positive trends in the post-intervention than the pre-intervention are observed in both graphs. This was verified independently for each of the four methods (i.e. injectable, pill, 
IUD, condom), hence the probability for it occurring randomly equals $.50 \times .50 \times .50 \times$ $.50=.06$, one-tailed.

Validity of Attributed Post-Choice Behavior. To assess possible biases in the clients' attribution of post-choice items to the provider, we analyzed the control items of the clinic exit interview, i.e., the four false alarm signs of the injectable that were included in the questionnaire and were asked in the case of clients who had chosen this method (e.g., Did the doctor tell you that you should immediately return to the clinic if you had blurred vision?). Figure 14 shows that, in the pre-intervention, the clients said Yes in response to half a control item on average, and this trend was maintained unchanged over the 19 weeks. In the post-intervention, the clients systematically increased their rate of Yes responding, and this was reflected both in the slope and altitude of the series.

Figure 14. Time Series for Client Attribution of Control Items to Physician Behavior in Pre- and Post-Intervention

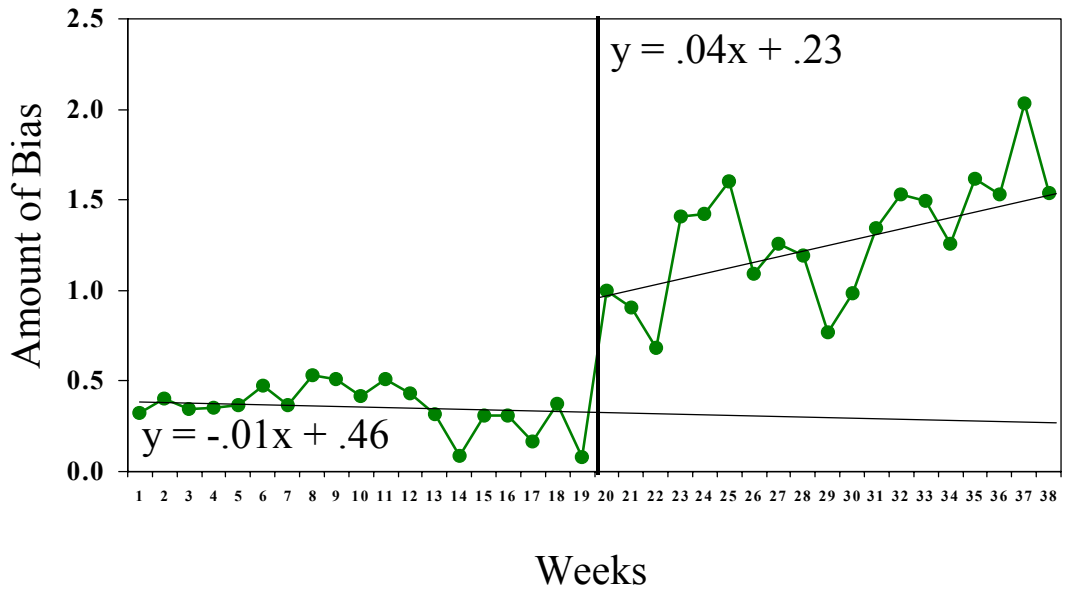

This result cannot be interpreted as a product of interviewer bias, for the interviewer had little chance to bias the Yes-No responses of the client. What it suggests is that a client's attribution pattern that can be understood recurring to the concept of halo, i.e., "the tendency to rate a person in about the same way on all traits because of a 
general, overall impression" (Guion, 1965, p. 99). In the present case the clients seemingly were impressed by an increased amount of post-choice information-exchange behavior on the part of the physician following initiation of the intervention.

Consequently, they applied their increased rate of Yes responding to the control items even in the absence of the specific provider behaviors referred to by such items. Contrasting with the greater personal significance of the items in the general quality of care scale, those pertaining to provider information-exchange on the method chosen were exclusively technical in nature. Hence, the client may have had many doubts when she tried to remember these technical items and probably responded on the basis of guessing.

\section{Client Knowledge Concerning the Method Chosen}

The client's knowledge concerning the method chosen was hypothesized to increase following improvements in the quality of care.

Changes in Client Knowledge. Figures 15 and 16 present time series for spontaneous recall pertaining to valid informational items on the injectable and the other three methods targeted for analysis (pill, IUD, and condom), i.e., what the client knew about the method chosen excluding the control items for the injectable. Negative preintervention trends were registered in both cases. These were reversed to positive after the intervention in the case of the injectable and to a less negative trend in the case of the other three methods. (the researchers verified that the intervention was followed by a more positive or less negative trend with respect to each of the four methods, $p=.06$, one-tailed.) On the other hand, the post-intervention curves did not attain the altitude of the early pre-intervention phase. Whereas the inflection of the curve invites attribution of causality to the intervention, the decrease in knowledge during the pre-intervention demands the search for an explanation that is not obvious.

Workload Hypothesis. At first sight, the increased provider workload that took place in the pre-intervention according to the IGSS service statistics could explain the decreased knowledge concerning the method chosen that was observed in this phase of the study. Given the need to see more clients, the counseling time available per client 
Figure 15. Time Series for Spontaneous Recall of (Valid) Injectable Items in Pre-Intervention and Post-Intervention

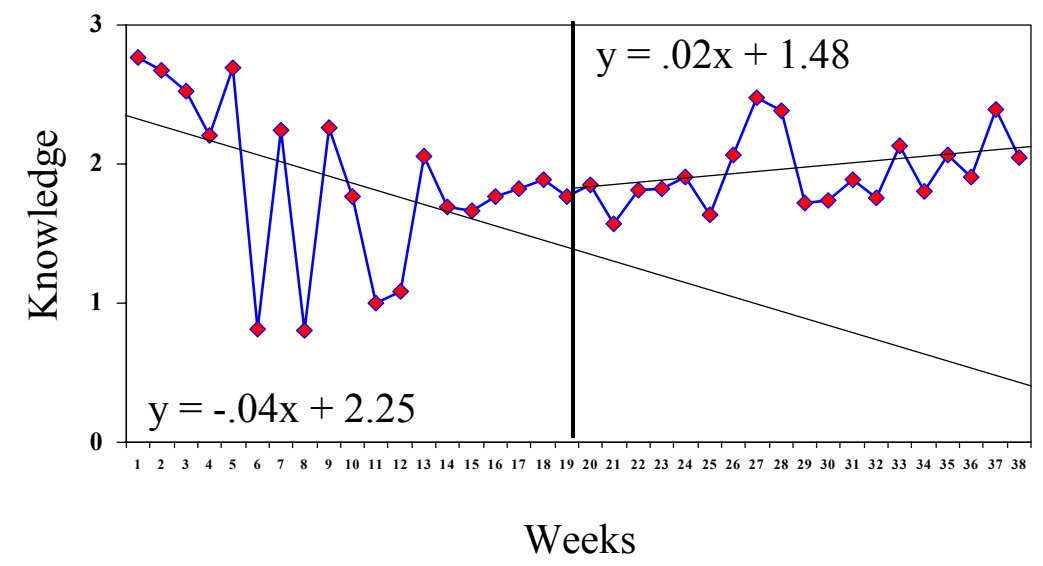

Figure 16. Time Series for Spontaneous Recall of Pill, IUD, or Condom Items in Pre-Intervention and Post-Intervention

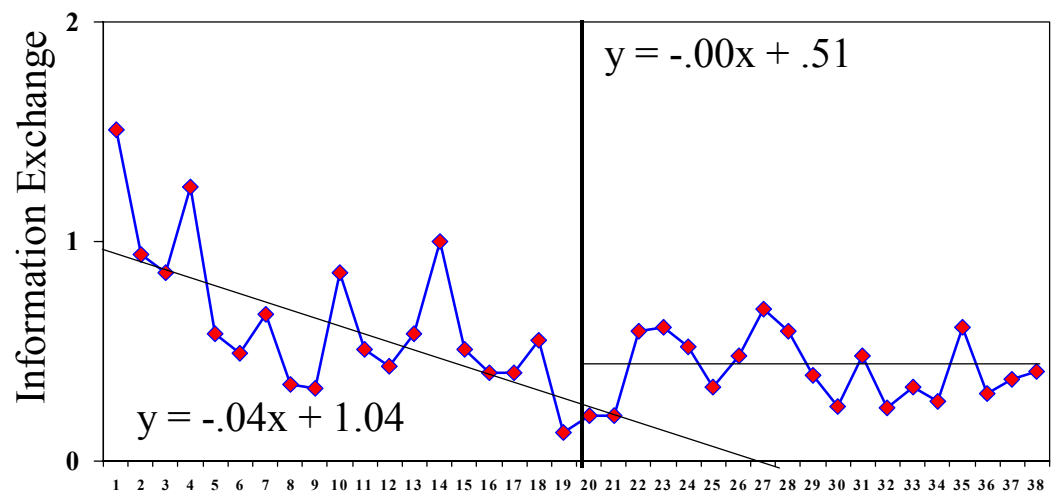

Weeks

diminished during the pre-intervention. Since there is evidence that neither the general quality of care nor the information-exchange concerning the method chosen diminished in this period, we can hypothesize that the provider was forced to talk more rapidly to 
convey the needed information about the method chosen, thus causing client informationoverload and a diminished capacity on her part to store the new information. As for the clients' increasing recall in the post-intervention, the increased time that would have been available per consultation in that period would have enhanced the quality of care and thus could account for the general inflection of the knowledge curves.

Yet, there are problems with the workload hypothesis. First, the general quality of care remained constant throughout the pre-intervention (Figure 5). How could the hypothesized increase in provider workload affect client knowledge and not the general quality of care? A second problem with the workload hypothesis emerges when we consider that the loss in client knowledge was already observed in the first six weeks of the pre-intervention (Figures 15 and 16). This interval corresponds to the last week of August, four weeks of September, and first week of October 2001, i.e., a period in which the number of new users had not yet importantly increased. Moreover, the family planning service statistics were contradicted by other measures of workload and thus do not guarantee validity.

Instrumentation Hypothesis. Since provider workload does not fully explain the decreased knowledge observed during the pre-intervention, another factor should have contributed to shape the configuration of this variable. Perhaps the interviewers adjusted their criteria for categorizing the clients' spontaneous recall as correct or incorrect responses as their experience in fieldwork increased. Whereas their other tasks in the interview consisted of simply marking clearly defined response options, in the measurement of client knowledge they had to undertake a complex judgmental task to categorize the client's spontaneous recall as a correct or incorrect response. More specifically, they might have started this task scoring too leniently and leveled their scoring later in the pre-intervention. To test this hypothesis, we analyzed the spontaneous recall of false alarm-signs of the injectable (control items). Figure 17 presents the time series for the false alarm-signs. The trend was close to zero both in the pre- and postintervention and suggests that the clients neither spontaneously mentioned these items when they were asked about the false alarm-signs nor that the interviewers produced false positive responses. 
Figure 17. Time Series for Client Knowledge of Control Items in Pre- and Post-Intervention

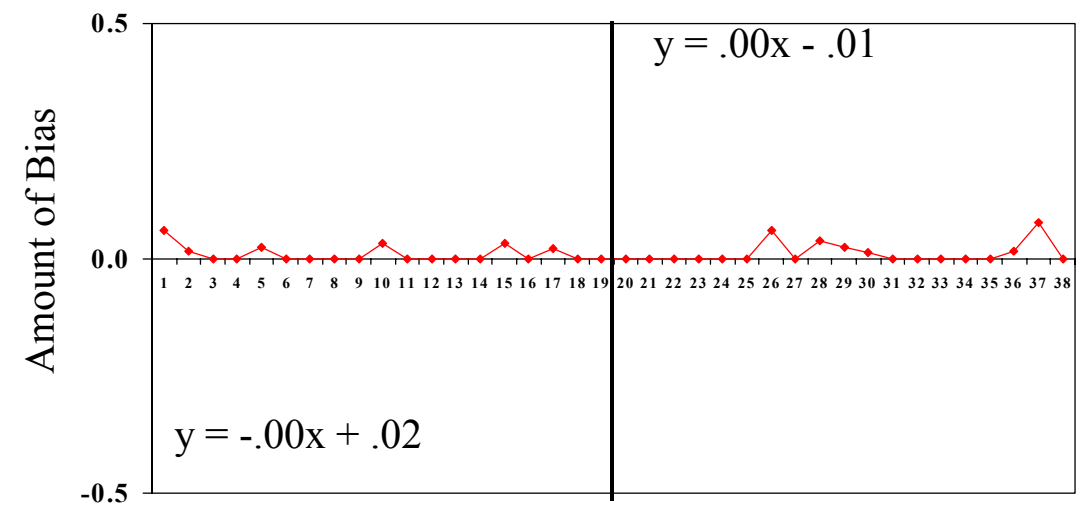

Weeks

On the other hand, instrumentation disturbances might have been produced by individual differences between interviewers that entered and left data collection at various points in time. The greater leniency of some of them in categorizing the clients' responses, and greater severity on the part of others, plus their respective adjustments over time, could have contributed to the final distorted configuration of the average knowledge scores. This clearly was the case of Interviewers 6 and 7, as Figure 18 shows. Their differences in scoring client knowledge during the first weeks of their participation in data collection are strikingly inconsistent. Interviewer 7 reported zero scores on average for weeks 5, 6, and 8 while Interviewer 6 gave averages over 1.5 in all these weeks. After a period of adjustment that for Interviewer 6 took two continuous weeks and for Interviewer 7 four or five discontinuous weeks, their scores converged in the second part of the pre- intervention. Their differences in leniency-severity reappeared in the postintervention. Interviewer 6 reentered data collection at a low point after a break and presented an ascending trend during the post-intervention. In contrast, the curve for Interviewer 7 continued to ascend in the post-intervention.

Figure 19 presents the injectable scores contributed by the six other interviewers. Important individual differences in scoring can be seen. Some of the 

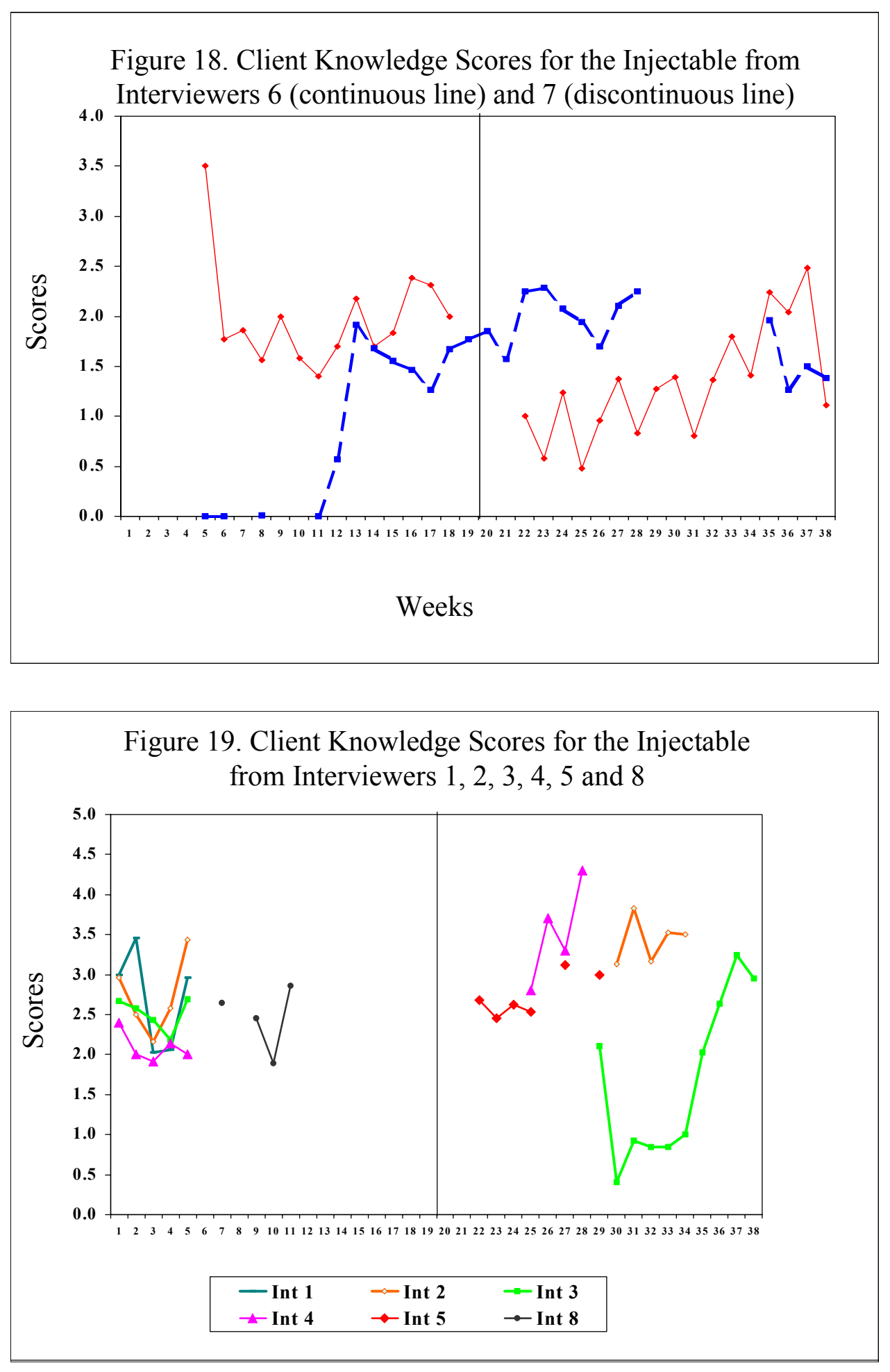

individual series for client knowledge are exactly the opposite to those for post-choice information-exchange attributed to the provider. This may have been structurally determined by the questionnaire. If the client provided a correct spontaneous-recall 
response concerning a trait of the method chosen, the item was excluded from the set of provider information-exchange questions.

\section{Use Rates and Continuation in Family Planning}

The client's continuation in family planning was hypothesized to increase following improvements in the quality of care.

Family Planning Use Rates. Considering at the baseline all the clients who, according to the social worker, had received a given method, or were given an appointment to receive that method, use rates were computed as the percentage of clients who, according to their responses on the calendar module of the follow-up interview, were using any family planning method (i.e., not necessarily the one indicated by the

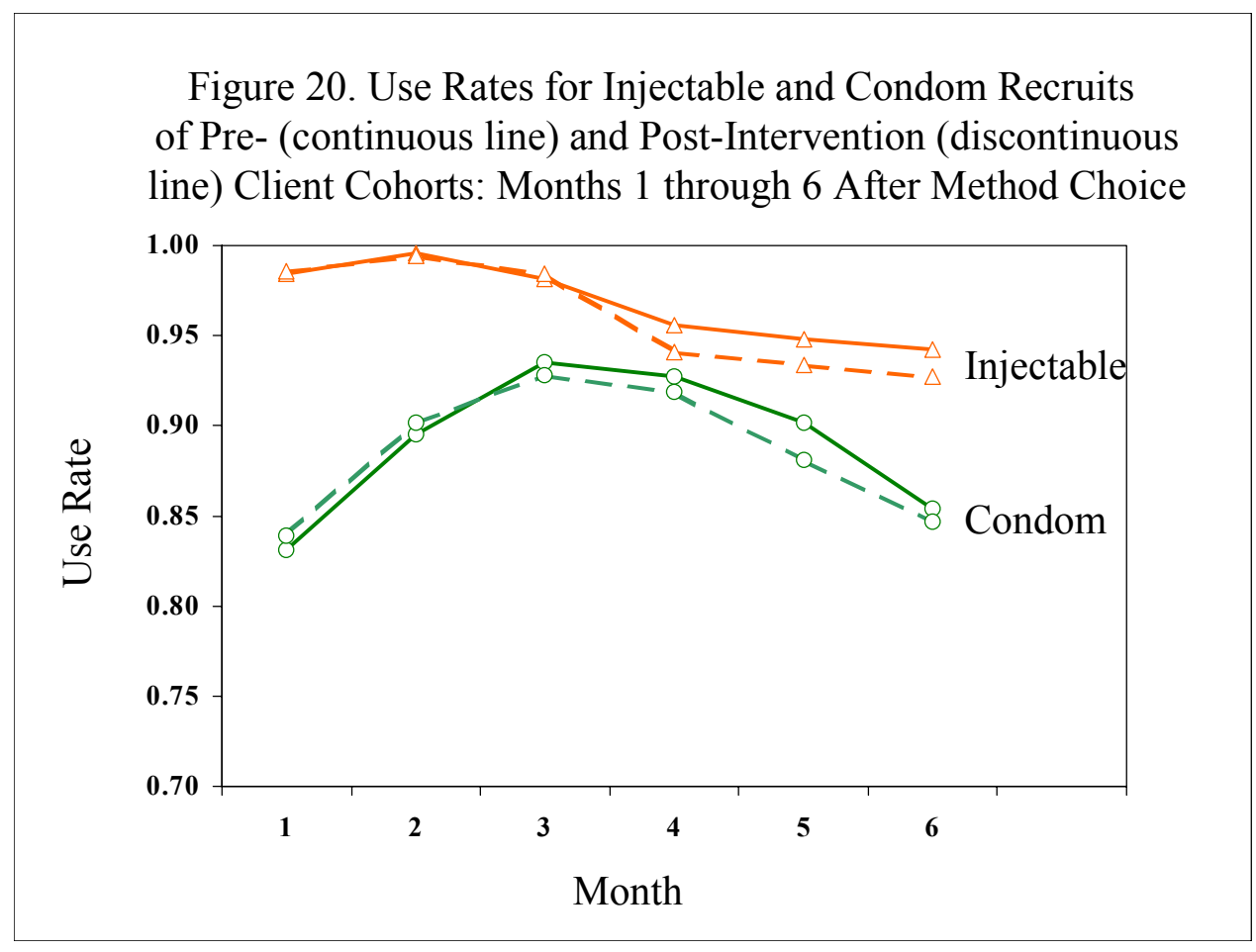

social worker at the time of recruitment). Figure 20 presents the family planning use rates at months one through six for the pre- and post-intervention clients who had been recruited as nominal users of the injectable $(\mathrm{N}=1,616)$ or the condom $(\mathrm{N}=359)$. For either method, the pre- and post-intervention curves were very similar despite that the clients had been included more than one year apart. On the other hand, the results were 
inconsistent with the hypothesis of the study. The difference between pre- and postintervention cohorts was not statistically significant for any method at any month despite the high number of nominal users of the injectable.

The use rates were very high in the case of these clients. The rates for the nominal users of the injectable ranged from .92 through .99 . This family planning method generally satisfies a long-term need of the client, i.e., a condition that does not change importantly over time. The curve for condom users evolved at a markedly lower altitude, ranging from .83 through .93 . The condom can be used to prevent pregnancy on a continuous basis but more generally to prevent pregnancy and sexually transmitted infections in occasional encounters. Use of this method, hence, will be contingent on the existence of the casual encounters. Additionally, at least during the pre-intervention, condoms were given at the hospital to clients who had chosen a natural family planning method to maintain them registered as family planning users in the hope that they would change their mind and would return for re-supply or a change of method. A combination of factors, consequently, may account for the difference in altitude between the injectable and condom curves.

The injectable is applied every three months. The fact that months 1,2 , and 3 , on the one hand, and months 4,5, and 6, on the other, do not present identical rates within the three-month period can be attributed to cases of clients who waited until the time of the appointment one month later to receive an injection. In other cases, the client may have chosen the injectable, used condoms, and then discontinued their use. For the set of nominal users of the condom, the use rate markedly increased from month 1 to month 2 and then to month 3 . This might be explained by the fact that in a number of cases the clients were given condoms for use while they became ready to use a primary method such as the IUD, injectable, or pill, or if they had chosen a natural method. Some might have not used the condom and started using the primary method weeks later.

Figure 21 presents the curves for the IUD $(\mathrm{N}=238)$ and the pill $(\mathrm{N}=97)$. Again, the results were inconsistent with the hypothesis of the study. The pre- and postintervention curves overlapped with each other throughout the study period either when the IUD or the pill were chosen at recruitment time. None of the comparisons was 


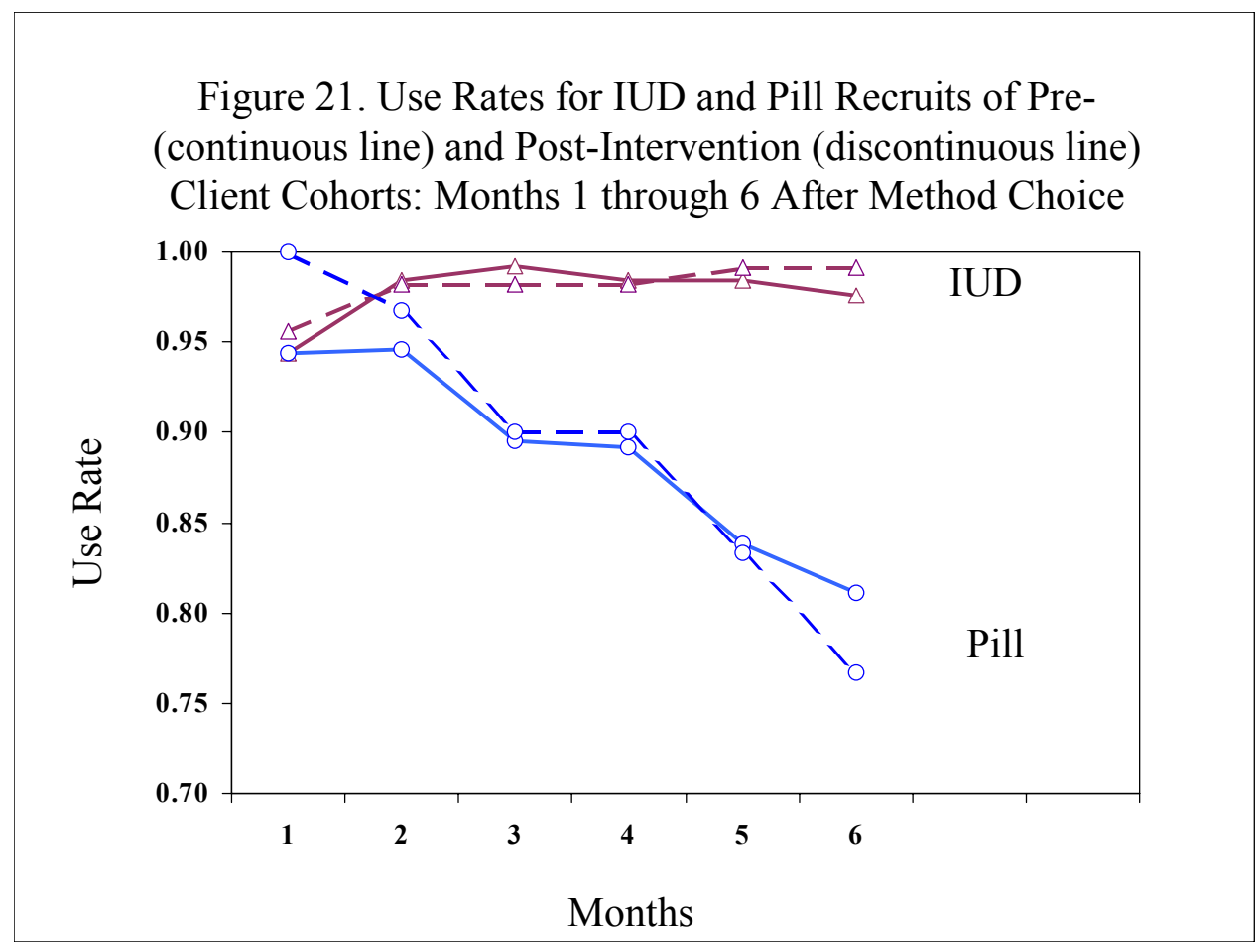

Figure 22. All-method Continuation Rates for Pre- and PostIntervention Cohorts at Months 1 through 6 After Method Choice

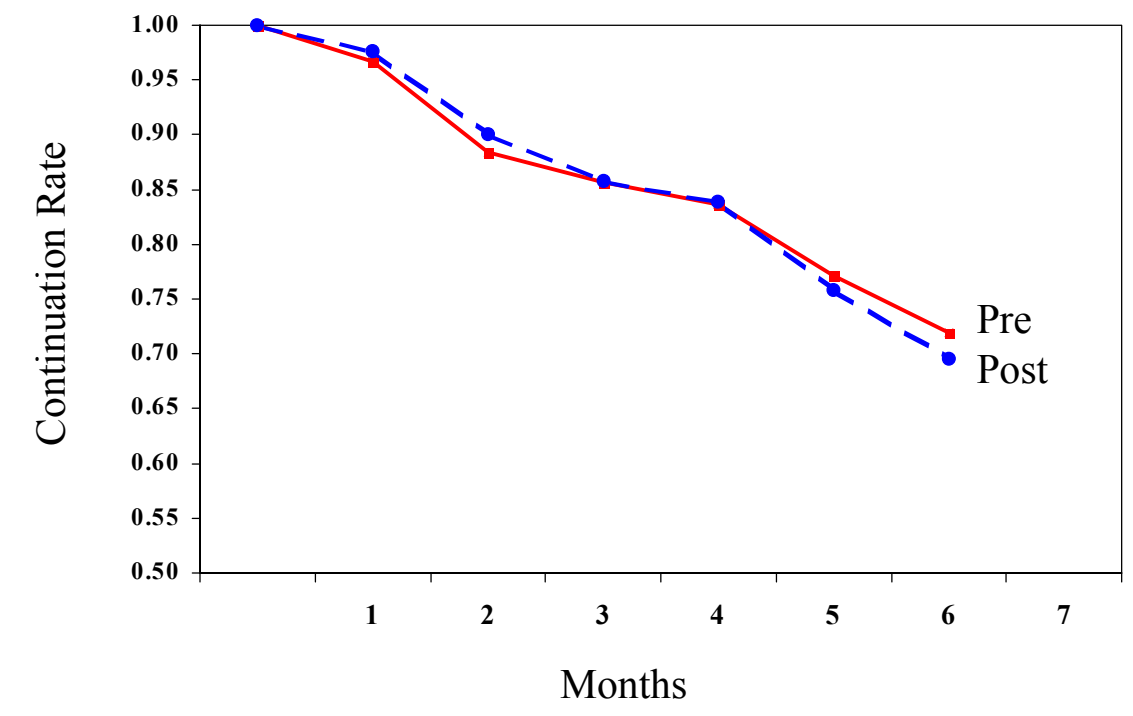

significant for any method at any month. The use of family planning was very high for clients that chose the IUD, who maintained the use rate between .94 and .99. On the other 
hand, the nominal pill users of both cohorts showed a marked discontinuation trend, falling in the extreme cases from 1.00 through .76 .

Family Planning Continuation Rates. The continuation analysis presented in this section compared the pre-intervention $(\mathrm{N}=1,384)$ and post-intervention cohorts $(\mathrm{N}=$ 1,756 ) in terms of segments of continuous use of family planning (which includes shifting methods). As is typical of survival functions based on life tables, monotonically descending curves emerged and only 72 percent of the segments of use reached month six. Contradicting the hypothesis of this study, the survival functions for the two cohorts were nearly undistinguishable (see Figure 22).

\section{Costs of the Intervention}

Table 2 provides information on the total costs of the intervention. Financial costs refer to actual expenditures by the FRONTIERS program to purchase staff and consultant time, materials and supplies, and other expenses including meals and snacks provided at meetings and workshops. If IGSS were to replicate the entire intervention in exactly the same manner in which FRONTIERS carried it out originally, these are the costs that IGSS would incur.

Table 2. Costs of the Intervention to Improve Counseling at the IGSS (in Guatemalan Quetzales)

Cost Items Plan/design Implementation Supervision

Financial Costs

Project Staff Intervention of Training of Trainees Total (FRONTIERS staff, consultants)

Administrative Staff

$$
10,665
$$$$
8,214
$$

24,158

(Frontiers support) Materials and Supplies 1,000 1,050 1,650 3,700

Meals and Venue Expenses

$\begin{array}{llll}1,050 & 4,500 & 2,000 & 7,550 \\ 2,446 & 2,984 & 2,400 & 7,830\end{array}$

Total Financial Costs Q.15,161

Q.16,748

Q.30,208

Q.62,117

Non-financial Costs IGSS Staff (designers, trainees and supervisors) Total Economic Costs 4,978 9,806 6,790 21,574 Q.20,139 Q.26,554 Q.36,998 Q.83,691 
Non-financial costs are associated with resources that IGSS already had purchased but had redeployed in order to support the intervention. For example, IGSS overall costs did not change when IGSS providers attended the workshops, since these employees are all salaried workers; but there is an opportunity cost associated with workshop attendance because staff could be providing services in the clinic rather than attending the training.

Overall, financial costs of Q.62,117 (US\$8,015) account for three quarters of the total intervention cost of Q.83,691 (US\$10,799). As is usually the case with trainingbased interventions, personnel costs account for the largest share of total costs. Financial costs of personnel (project staff plus administrative staff) represent $69.3 \%$ of total financial cost, a share that rises to $81.6 \%$ of total economic cost when the non-financial costs of IGSS staff are added. The remaining categories of materials/supplies and meals/other venue expenses each account for approximately 9 percent of total costs.

The supervision phase exhibits the highest cost of the three intervention phases, which reflects the high priority that the IGSS and the FRONTIERS program placed on assuring that the trained providers were applying the new counseling model correctly and consistently. The next-costliest phase of the intervention was the implementation of training; this was driven by financial costs of trainers as well as the non-financial costs of IGSS trainees.

\section{Utilization}

Considering the improvements of the quality of care that were already visible in supervision visits to the family planning consultation rooms of the hospital, the IGSS decided to scale-up the intervention nationally. An extension program started in February 2003 with preparations to conduct training of trainers for three central level officers and 36 trainers in Guatemala City, Escuintla, and Suchitepéquz. This will be followed by the training of 150 providers from districts of Guatemala, Petén, Progreso, Zacapa, Chiquimula, Escuintla, Chimaltenango, Sacatenéquez, Jutiapa, Mazatenango, San Marcos, Quetzaltenango, and Quiché. The program was completed in September 2003. 


\title{
V. CONCLUSIONS AND RECOMMENDATIONS
}

\author{
Conclusions
}

\section{Provider training on the job aids-assisted Balanced Counseling Algorithms enhanced the quality of care at the hospital.}

The enhancement of the quality of care was documented by three indicators. First, the general quality of care improved the week of initiation of the intervention and consistently maintained a higher level in the post-intervention than in the pre-

intervention. Second, the level of provider activity in the post-choice phase of counseling increased and maintained an ascending trend during the post-intervention. Third, the contraceptive methods received by the clients more rigorously reflected their early personal choices in the post-intervention than in the pre-intervention.

The improvement of the quality of care is attributable to changed physician behavior, which is reflected in changes in physician time-use.

Since the client first chose a method with the social worker, the algorithm required the physician to pay special attention to the method chosen. The clients observations indicated in the post-intervention period of the study an increased level of post-choice counseling on the part of the physicians. This change in physician behavior is reflected in changes in physician time-use. The time-motion study registered an increased dedication to clients from 74 minutes in the pre-intervention to 108 minutes in the post-intervention. The Balanced Counseling Strategy is a thorough counseling model that causes longer session lengths than usual (e.g., León et al., 2002, 2003). To dedicate more time to clients, the physicians reduced the time dedicated to personal matters. Even with this change, physicians still had more than 25 percent of their paid time available to serve additional clients.

\section{To improve the quality of care, the social workers implemented the job aids-assisted Balanced Counseling Algorithm without major changes in their use of time.}

Clients reported a consistently higher quality of care received when they were seen by both the social worker and the physician than when they were seen by the physician alone, regardless of period of the study. This reveals that the social workers consistently contributed to the quality of care. They also specifically contributed to the improvement 
of the quality of care after the intervention. Indeed, the general quality of care reported by clients under dual service showed a jump from pre-to post-intervention that was more clearly defined than in the reports from clients who had received services from the physician alone. However, social workers maintained a constant dedication to clients of about 154 minutes in pre- and post-intervention. Also, the number of minutes dedicated to administrative tasks remained nearly constant. They seemingly had a greater individual workload than the physicians did and, when the new counseling model was introduced, implemented it without increasing the time spent per client.

\section{Provider output was not changed by the intervention.}

Some contradictions were observed between the number of new method users according to the IGSS' service statistics, the number of consultations registered in the time-motion study, and the number of consultations per physician shift calculated on the basis of physician daily reports. The number of new family planning users according to the service statistics showed a dramatic decline after the intervention. The combined data available, however, suggest that this reflected a seasonal trend in reporting service statistics and not an intervention effect. A similar but less pronounced decline occurred in the number of consultations per physician shift.

\section{The enhanced quality of care did not reduce the share of the injectable in the method mix.}

According to the exit interviews, the percentage of new injectable users increased in the post-intervention along with the improvements in the quality of care. According to the service statistics, no important change was registered. Both findings counter the hypothesis that enhancements of the quality of care would cause a significant reduction in the choice of the injectable. This suggests that the increased participation of the injectable in the historic method mix at the hospital reflected the benefits perceived by the client rather than a bias on the part of the provider.

\section{Client knowledge improved after the intervention but causation is ambiguous.}

A decrease in client knowledge concerning the method chosen was observed throughout the pre-intervention. This probably reflected an instrumentation bias attributable to diverse scoring criteria used by diverse interviewers who entered and left data collection 
at different points in time. Measurement of this variable required complex judgmental tasks of the provider and thus was unreliable. On the other hand, client knowledge improved in the post-intervention. This could have been due to the intervention, to more counseling time available to the provider as a result of decreased workload, and/or to instrumentation bias.

\section{The improvement of the quality of care was not followed by enhanced client continuation.}

Neither the use rates from month one through month six after the client's method choice nor the continuation rates calculated on the basis of life tables for the same months showed significant differences between the pre- and post-intervention cohorts. Given the rather close similarity of the use rates and survival functions between the pre- and postintervention client cohorts, unreliability of measurement can be ruled out as a cause of this failure to support the study hypothesis. The discontinuation in the case of nominal pill users was particularly pronounced. The results can be explained by two factors: 1. An overwhelming majority of clients, i.e., those who had chosen the injectable or the IUD, showed high levels of continuation that may represent its natural upper limit; and 2. A minority of clients, i.e., those who had chosen the pill or condoms, showed discontinuation patterns that may obey to factors not addressed by the job aids-assisted Balanced Counseling Algorithms.

\section{The improvement of the quality of care required a costly investment.}

Because of the absence of a measurable impact of the intervention on continuation rates, we did not carry out an incremental cost-effectiveness analysis using changes in continuation as the measure of effectiveness. But results of the cost study showed that replication will require IGSS to expend resources, although at a lower cost than observed in the study. The main reason is that the replication will be carried out almost entirely by locally hired staff, who receive lower remuneration than the international consultants that designed and directed the original intervention with IGSS. Also, fewer staff hours will be used to adapt the counseling model to other IGSS hospitals and to train IGSS providers in the workshops. Using local wage rates and taking into account the changes mentioned 
above, we estimate that the cost of replicating the intervention per IGSS hospital would be approximately US $\$ 3,750$ at current exchange rates.

\section{Recommendations}

\section{Monitor provider implementation of the job aids-assisted Balanced Counseling Algorithms.}

Physicians had to use personal time while on the job to comply with the requirements of the new counseling model. Social workers did not have much personal time to spare, hence they had to squeeze the new counseling behaviors into a crowded shift agenda. Long-term adaptation of the providers to the new situation must be followed-up to preempt possible problems in the implementation of the job aids-assisted Balanced Counseling Algorithms.

\section{Monitor provider output.}

The changes observed in provider time-use may have implications for costs of the intervention in the longer term. Since the intervention increased the duration of the provider-client interaction, this may eventually reduce the capacity of the providers to cope with the client workload and could put pressure on IGSS to hire additional clinical staff.

\section{Adjust institutional policy and goals to the reality of client preferences.}

IUD insertions are more cost-effective than the delivery of the injectable. Given the recent increased prevalence of the injectable at the expense of the IUD, a general reaction has been to assume provider bias and consider reversals of this situation via intensive provider training and other strategies. Yet the evolution of the method mix at the IGSS reflected client preferences, not provider bias. The IGSS must learn to take advantage of the new method-mix situation rather than attempting to change it.

\section{Test reformulated post-choice strategy.}

The reversal of the client knowledge trend in the post-intervention was somewhat disappointing in terms of level of achievement of client learning outcomes. This raises some doubts concerning the appropriateness of the post-choice instructions contained in 
the Balanced Counseling Algorithms. Perhaps reading the method pamphlet in full with the client causes information overload and thus prevents adequate information storage. The IGSS could test an alternative post-choice strategy whereby the provider just presents one important item per section of the pamphlet and encourages the client to read the pamphlet in full when she has the time to do it carefully.

\section{Pay particular attention to clients who choose oral contraceptives or condoms.}

The level of discontinuation of family planning on the part of the clients who choose the pill in the consultation should be a source of concern for the program. Further research is required to develop a specific remedial strategy. Similar is the case of the nominal condom users.

\section{References}

Aldana M \& Rosal R. (2002) Tablas de eventos obstétricos y primeras consultas en la Clínica Postparto/Postaborto del Hospital de Gineco-Obstetricia y otros establecimientos del Instituto Guatemalteco del Seguro Social, Guatemala, agosto 2000 - marzo 2002.

Blanc AK, Curtis S, Croft T (1999) Does contraceptive discontinuation matter? Quality of care and fertility consequences. MEASURE Evaluation Technical Report Series, No. 3. Chapel Hill: Carolina Population Center, University of North Carolina at Chapel Hill.

Bonatto C. (2003) Estadísticas 2001-2002 de usuarias nuevas de planificación familiar por método recibido, Hospital de Gineco-Obstetricia del Instituto Guatemalteco del Seguro Social, Guatemala.

DHS-Guatemala (1999) Guatemala: Encuesta nacional de salud materno infantil 19981999. Guatemala: INE, MSPAS, USAID, UNICEF, UNFPA, Macro International.

Guion RM. (1965) Personnel testing. New York: McGraw-Hill.

Jain AK (1989) Fertility reduction and the quality of family planning services. Studies in Family Planning 20, 1: 1-16.

León FR, Ríos A, Zumarán A, \& Bratt J. (2002) Improving Provider-Client Interactions At Peru MOH Clinics: Extent, Benefit and Cost. Lima: Population Council, 31 August

León FR, Brambila C, De la Cruz M, Bratt J, García Colindres J, Vásquez B, \& Morales C. (2003) Improving Provider-Client Interactions at Guatemala MOH Clinics: Extent and Cost. Guatemala: Population Council, 31 January 